\title{
A SURVEY OF BALLUTE TECHNOLOGY FOR AEROCAPTURE
}

\author{
Reuben R. Rohrschneider and Robert D. Braun \\ Georgia Institute of Technology, Guggenheim School of Aerospace Engineering \\ 270 Ferst Dr., Atlanta GA 30332-0150, USA \\ reuben_rohrschneider@ae.gatech.edu,robert.braun@aerospace.gatech.edu
}

\begin{abstract}
Ballute aerodynamic decelerators have been studied since early in the space age (1960's), being proposed for aerocapture in the early 1980 's. Significant technology advances in fabric and polymer materials as well as analysis capabilities lend credibility to the potential of ballute aerocapture. The concept of the thin-film ballute for aerocapture shows the potential for large mass savings over propulsive orbit insertion or rigid aeroshell aerocapture. The mass savings of this concept enables a number of high value science missions. Current studies of ballute aerocapture at Titan and Earth may lead to flight test of one or more ballute concepts within the next five years. This paper provides a survey of the literature with application to ballute aerocapture. Special attention is paid to advances in trajectory analysis, hypersonic aerothermodynamics, structural analysis, coupled analysis, and flight tests. Advances anticipated over the next 5 years are summarized.
\end{abstract}

\section{NOMENCLATURE}

$\begin{array}{ll}\mathrm{A} & =\text { projected frontal area } \\ \mathrm{C}_{\mathrm{D}} & =\text { drag coefficient } \\ \mathrm{C}_{\mathrm{L}} & =\text { lift coefficient } \\ \mathrm{C}_{\mathrm{m}} & =\text { pitching moment coefficient } \\ \mathrm{CFD} & =\text { computational fluid dynamics } \\ \mathrm{CG} & =\text { center of gravity } \\ \mathrm{CSD} & =\text { computational structural dynamics } \\ \mathrm{d} & =\text { payload base diameter } \\ \mathrm{DSMC} & =\text { direct simulation Monte Carlo } \\ \mathrm{FEA} & =\text { finite element analysis } \\ \mathrm{l} & =\text { tow line length } \\ \mathrm{L} / \mathrm{D} & =\text { lift to drag ratio } \\ \mathrm{M} & =\text { vehicle mass } \\ \mathrm{p} & =\text { ballute fill pressure } \\ \mathrm{PBO} & =\text { polybenzoxazole } \\ \mathrm{PIBO} & =\text { polyimidobenzoxazole } \\ \mathrm{q} & =\text { dynamic pressure }=0.5 \rho \mathrm{V}^{2} \\ \mathrm{r} & =\text { minor radius of torus } \\ \mathrm{R} & =\text { major radius of torus } \\ \mathrm{Re} & =\text { Reynolds number } \\ \mathrm{St} & =\text { Stanton number } \\ \mathrm{TPS} & =\text { thermal protection system } \\ \mathrm{V} & =\text { velocity }\end{array}$

$\alpha \quad=$ angle of attack

$\beta \quad=$ ballistic coefficient, $\mathrm{M} / \mathrm{C}_{\mathrm{D}} \mathrm{A}$

$\gamma \quad=$ ratio of specific heats $\left(\mathrm{C}_{\mathrm{p}} / \mathrm{C}_{\mathrm{v}}\right)$

$\rho \quad=$ density

\section{INTRODUCTION}

The concept of using aerodynamic lift and drag to effect a change in orbital energy or plane is classified as aeroassist. First introduced in 1960, aeroassist techniques were shown to have substantial mass savings over propulsive methods in $[1,2]$. Many types of aeroassist trajectories exist including direct entry, entry from orbit, aerocapture, aerobraking and aero-gravity assist. This paper's focus is aerocapture.

In an aerocapture manuever, aerodynamic forces are used to decelerate a vehicle from its hyperbolic approach trajectory into a closed orbit about a planet in a single atmospheric pass. The mission profile is illustrated in Fig. 1, and shows the small propulsive periapsis raise manuever required to achieve orbit. The velocity increment removed during the atmospheric pass can be controlled by modulating the vehicle's aerodynamic lift (using either angle-of-attack or bank angle control) or changing the vehicle drag during the atmospheric pass. Aerocapture subjects an orbiter to much higher deceleration and heating (both heat rate and heat load) than aerobraking due to the large velocity reduction achieved in a single pass.

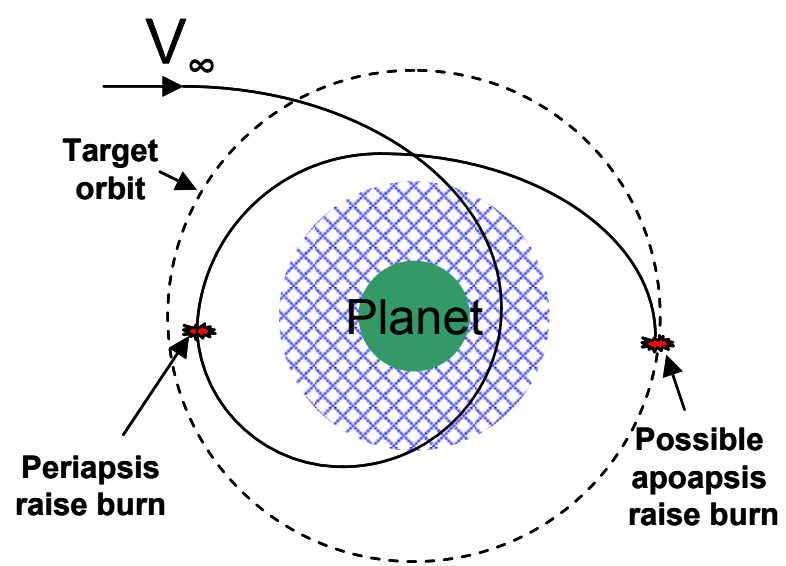

Figure 1. Aerocapture mission profile. 
The Goodyear Aerospace Corp. coined the term "ballute" (a contraction of "balloon" and "parachute" which the original ballute closely resembles) for their cone balloon decelerator in 1962 [3]. The term has become popular in the literature and now typically refers to any inflatable drag device for high speed deceleration. In the present literature ballutes are divided into clamped and trailing types, as illustrated in Fig. 2.

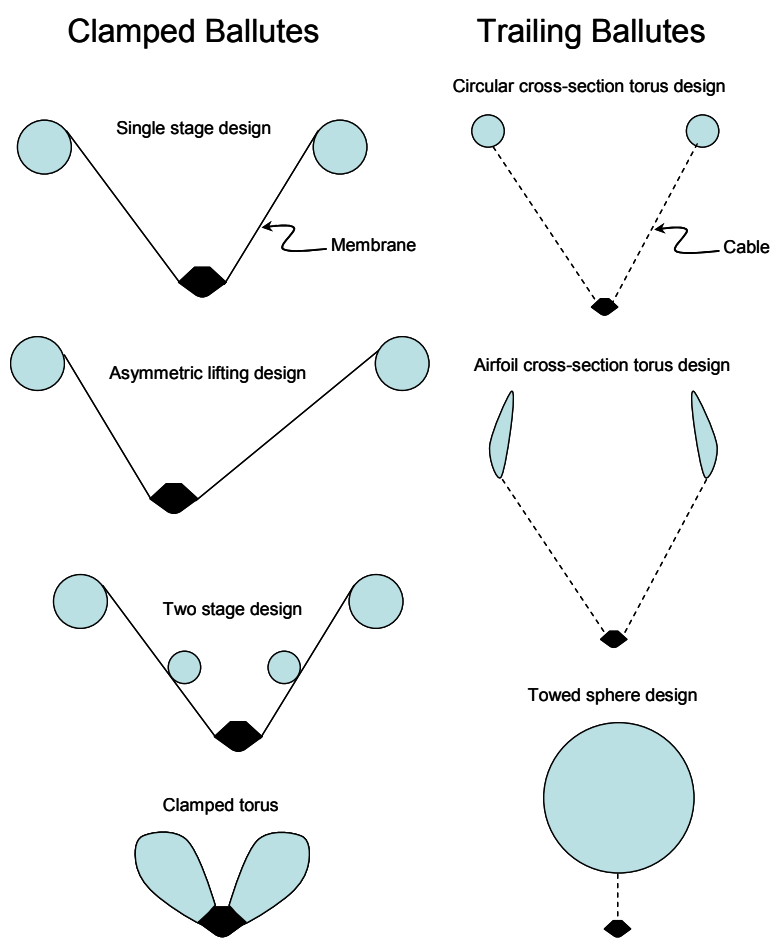

Figure 2. Examples of clamped and trailing ballutes.

In 1982, Walberg reviewed the aeroassist state of the art, including aerocapture for planetary entry and orbit insertion [4]. Missions to Mars, Saturn (via Titan aerocapture), Uranus, and Venus were reviewed, and all showed significantly reduced launch mass compared to an all propulsive mission (often by a factor of two).

In [5] several missions are identified from the NASA Space Science Strategic Plan [6] that require orbital insertion or entry at planets with atmospheres, and which could benefit from the mass savings of aerocapture. Mass savings of more than a factor of two for the orbit insertion system are realized for these missions with incorporation of thin-film ballute technology. Ref. [5] also demonstrates that a significant entry corridor exists for each mission where the steep entry limit is the material temperature limit and the shallow entry achieves the required velocity decrement without releasing the ballute. In [7] Hall, Noca, and
Bailey compare the mass and cost of aerocapture to chemical propulsion, chemical propulsion with aerobraking, and solar electric propulsion options. Ten planetary missions are studied and include insertion into circular (1) and highly elliptic (2) orbits at each feasible body. The study concludes that aerocapture is enabling for three missions $(\Delta \mathrm{V}=6$ to $17 \mathrm{~km} / \mathrm{s})$, enhancing for five missions $(\Delta \mathrm{V}=2.4$ to $4.6 \mathrm{~km} / \mathrm{s})$, and not helped by two of the missions $(\Delta \mathrm{V} \leq 1.4 \mathrm{~km} / \mathrm{s})$. Fig. 3 shows the mass and cost savings afforded by aerocapture over the best non-aerocapture option for each mission that benefits from aerocapture. Rigid aeroshells are used for aerocapture at all planets.

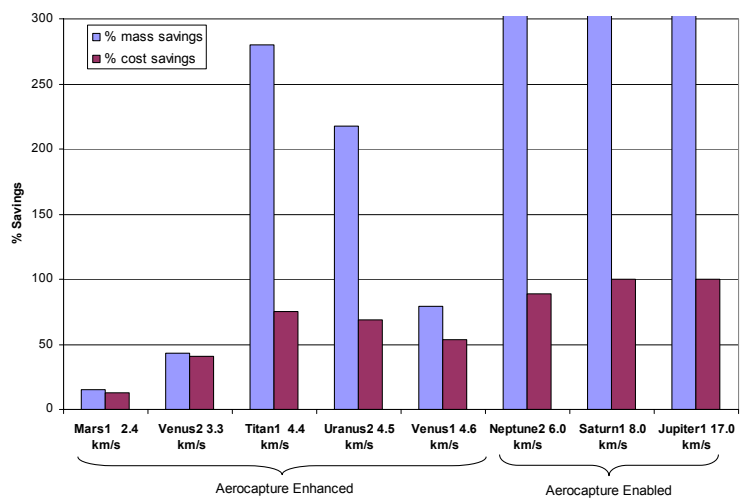

Figure 3. Percent mass and cost savings over a nonaerocapture option for planetary missions using rigid aeroshell aerocapture. [7].

\subsection{Early Ballute Development}

The instability and low drag of supersonic parachutes [8] and the desire to recover high speed, high altitude payloads led to the testing of towed spherical balloons as high speed drag devices by McShera and Keyes [9] in 1961. Many other early tests and studies demonstrated the good supersonic stability characteristics of the ballute $[10,11,12,13$, and 14].

The advantages of the low ballistic coefficient $(\beta)$ were utilized by [15] as a supersonic decelerator for Mars entry. Both trailing and attached ram-air inflated configurations constructed of Nomex or Dacron cloth coated with Viton or Neoprene were considered. A range of entry conditions were considered with a target of reaching Mach 1 at 20,000 $\mathrm{ft}$ altitude. All configurations were able to meet the target altitude for material temperatures less than $450^{\circ} \mathrm{F}$ encountered when deployed at speeds up to Mach 5. In 1968, Alexander reviews the test envelope of clamped fabric ballutes [16]. Tests were conducted with metal ballutes up to Mach 10, but fabric ballutes were not been tested at 
conditions exceeding Mach 3 flight conditions. In [17] the drag characteristics of the ballute and parachute are summarized as a function of Mach number and ballutes are shown to be more effective decelerators than parachute at speeds above Mach 1.5. The mass delivery advantage of using a supersonic clamped ballute is shown in $[17,18]$ for Mars entry. Mass advantages in excess of $15 \%$ are discovered when deploying a clamped fabric ballute at Mach 5 in place of a parachute at Mach 2.

Recognizing the potential mass and operational advantages of a ballute system, [19] and [20] proposed ballute concepts for aerocapture. Ref. [21 ] first proposed the use of a clamped ballute for entry from orbit in 1963 as a single-use personal space rescue vehicle. The concept consisted of a flight seat for a space-suited astronaut around which a clamped ballute inflated. The system was designed to land without a parachute and utilized an inflatable pad to limit impact acceleration. The concept was later expanded and refined for recovery of both men and payload in $[22,23$, and 24].

\subsection{Ballute Aerocapture}

Traditionally, aerocapture has been analyzed using a rigid aeroshell similar to those used for entry applications $[25,26]$. Lift is necessary to control the energy dissipated in the atmosphere in the presence of uncertainties, and so axisymmetric shapes are flown at an angle of attack. French and Cruz showed that an L/D of about 1.5 maximizes the accuracy of the atmospheric exit conditions [27]. Refs [28, 29, 30, 31, 32, and 33] show that sufficient accuracy can be achieved with low $\mathrm{L} / \mathrm{D}$ vehicles $(\mathrm{L} / \mathrm{D}=0.3)$ for Earth and Mars applications.

In [4], Walberg points out that one of the most difficult implementation aspects of aerocapture mission design is packaging an orbiter's deployable components inside a rigid aeroshell. To mitigate the packaging concerns of a rigid aeroshell, early ballute aeroassist studies used a clamped, coated Kevlar fabric ballute with a forward facing rocket engine to produce a low enthalpy boundary layer over the vehicle. The center of pressure of this configuration allowed a more aft $\mathrm{CG}$, and the less restrictive geometry made packaging easier. These early studies focused on reducing the orbital energy from geosynchronous Earth orbit to low Earth orbit. Ref. [19] showed that drag could be varied using engine throttling. Because this would impose a mass penalty, variable inflation pressure was specified instead. Even with the low enthalpy boundary layer produced by the engine the Kevlar fabric required a quartz outer layer and insulation to maintain its structural integrity.

Kustas et al have explored the clamped ballute configuration for Mars entry in [34] and [35]. The configurations considered consist of single and double attached toroids as shown in Fig. 4. Trajectory analysis indicated a peak heat rate of $35 \mathrm{~W} / \mathrm{cm}^{2}$ and a multi-layer insulation strategy was specified to protect the spacecraft and ballute. Kustas et al show a mass savings of $43 \%$ over a traditionally designed SLA-561V heatshield of the same size.
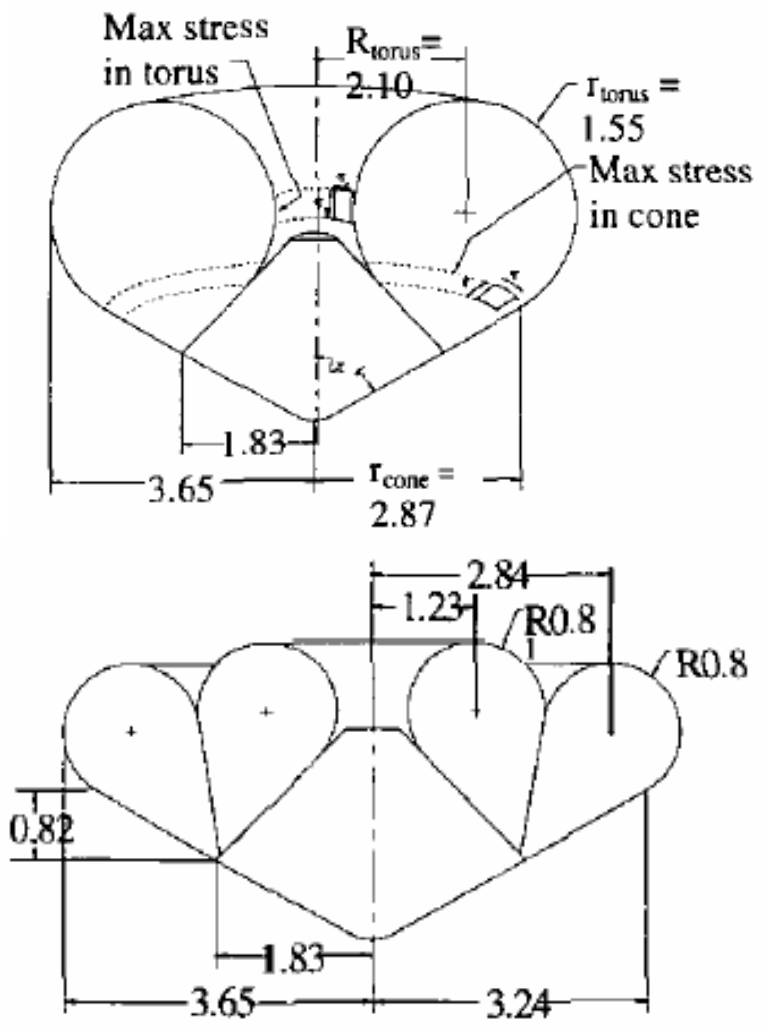

Figure 4. Clamped ballute configurations for Mars entry [34].

The low $\beta$ of ballute aerocapture results in deceleration higher in the atmosphere and with significantly reduced heating rate on the spacecraft. In [36], McRonald used this principle to design ballutes for entry and aerocapture at Mars and Pluto, and discovered that a ballute with a diameter 10 times that of the spacecraft (resulting in a $\beta 100$ times lower than that of a rigid aeroshell) could realize a heat rate 100 to 10,000 times less than with a rigid aeroshell.

Fig. 5 shows the heat rate for a Mars mission using a ballute for aerocapture. The lower curves are for heat 
rate and the upper curves are stagnation pressure. The vehicle numbers represent spherical towed ballute/spacecraft combinations with $\beta$ decreasing from 5.0 to $0.05 \mathrm{~kg} / \mathrm{m}^{2}$ for vehicles 1 to 6 respectively. As noted previously, lower $\beta$ leads to lower heat rate. Heating rates below $4 \mathrm{~W} / \mathrm{cm}^{2}$ are readily obtained for a ballute while heating rates of near $40 \mathrm{~W} / \mathrm{cm}^{2}$ [37] are obtained for rigid aeroshell aerocapture. The reduced heat rate eliminates the need for an ablative thermal protection system encompassing the spacecraft and relaxes packaging requirements. Furthermore, this low heat rate allows materials to be radiatively cooled to around $500^{\circ} \mathrm{C}$.

References [ 38 ] and [ 39 ] present properties of polybenzoxazole (PBO), polyimidobenzoxazole (PIBO), Mylar, and Kapton thin film polymers at temperatures up to $500^{\circ} \mathrm{C}$ for balloon applications on Venus. These materials are also well suited for ballute construction. Entry and aerocapture at Venus and Neptune are examined in [40] and [41] with ballute systems constructed of PBO and Kapton. The analysis at all four planets show that ballute mass to entry mass fractions can be in the $10-20 \%$ range. Fig. 6 demonstrates the ballute to entry system mass fractions possible for aerocapture at Neptune. Two other ballute configurations were examined by McRonald, the lenticular and toroidal ballute. They are depicted in Fig. 7 and have the goal of reducing the inflation gas mass compared to the spherical ballute.

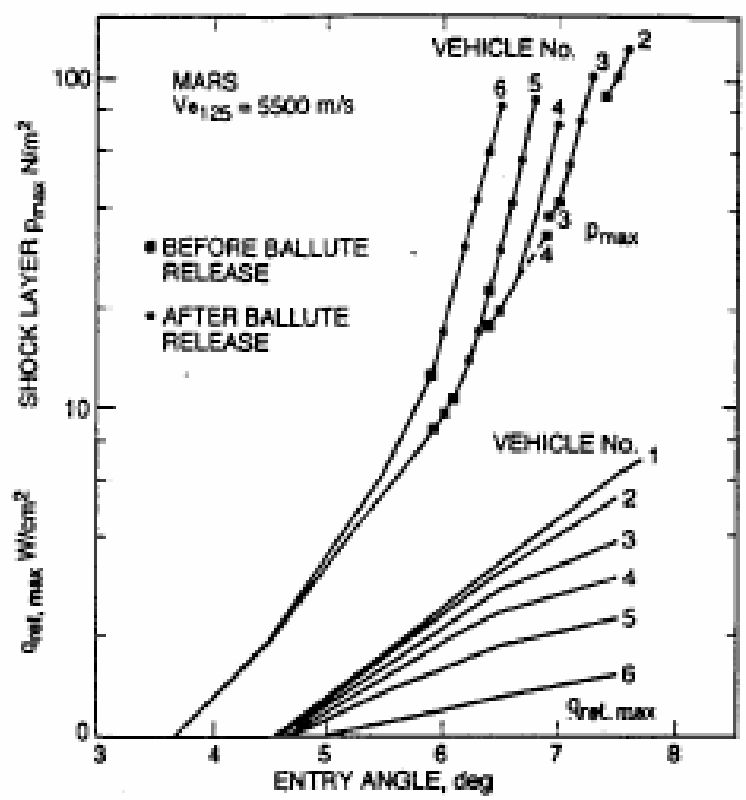

Figure 5. Peak heat rate and pressure for spherical thin film ballute aerocapture and entry at Mars [36].

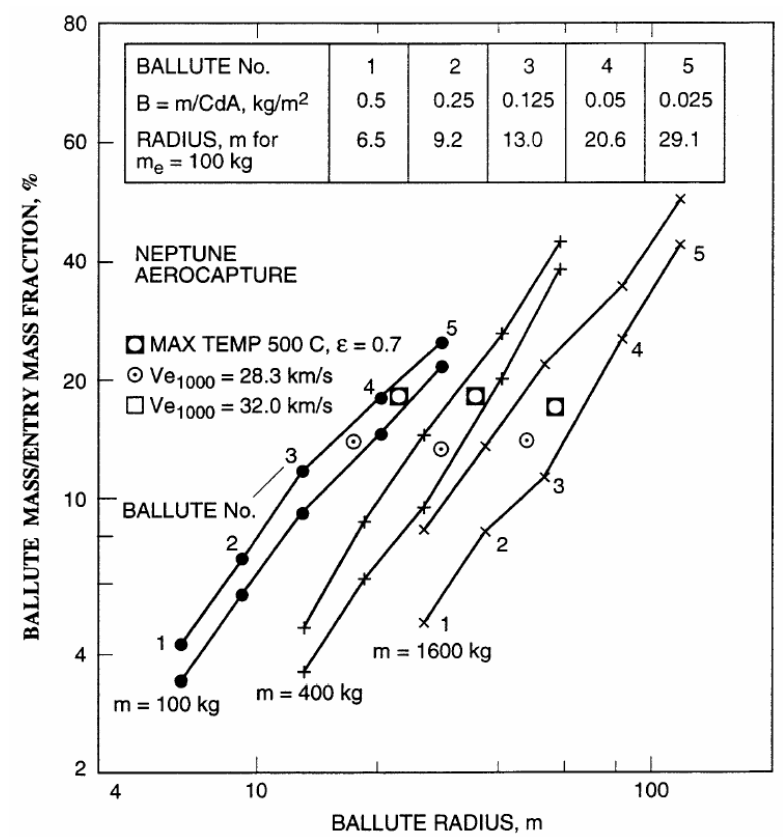

Figure 6. Ballute mass fraction (ballute mass/entry mass) for Neptune aerocapture [41].

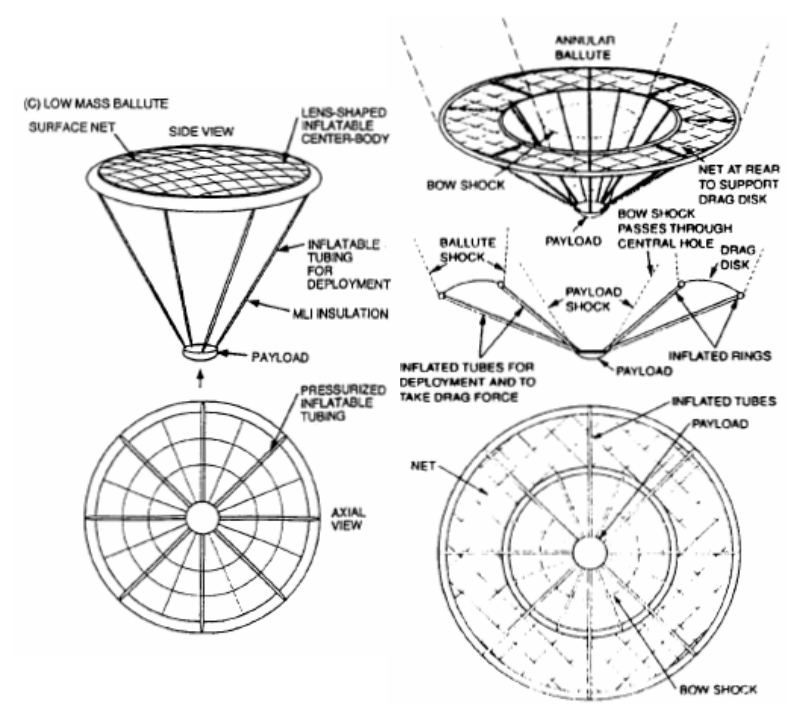

Figure 7. Lenticular (left) and toroidal (right) ballutes designed to reduce inflation gas mass $[36,41]$.

\subsection{Ballute Aerocapture Technical Challenges}

Despite the promising outlook portrayed in papers by McRonald, Hall and Le, and Kustas et al, much of the ballute analysis has been at the conceptual design level with little subsystem work to better define system mass and implementation options.

In 2000, Hall conducted a review of ballute technology for planetary aerocapture [42]. After an overview of 
ballute technology, Hall summarizes the current state of ballutes with $10 \mathrm{key}$ technical issues that need to be resolved for planetary aerocapture. A summary follows:

1) Determination of optimal ballute shape:

Several ballute shapes have been proposed in the literature with various advantages. Issues include tether heating, system mass, and drag characteristics.

2) Survivability of the ballute material:

Can thin-film membrane materials handle the heat produced? Expanded material testing is needed, and more accurate heat rates are needed to determine actual material temperature, including the impact of radiative heating on these large configurations.

3) Flow stability:

Large scale flow instability, such as vortex shedding, can cause motion and orientation changes of the ballute/spacecraft system. Smaller scale instability has also been discovered due to shock-shock interaction. Preliminary results suggest that this can be avoided by using a toroid of proper geometry, but further studies are needed. So far studies have assumed ballutes are rigid, but aeroelastic phenomenon need to be explored.

4) Ballute system mass:

Preliminary results indicate significant mass savings over both propulsive orbit insertion and rigid aeroshell aerocapture, but more detailed analysis is necessary. Changes in ballute shape, size, or inflation pressure could have a significant impact on the system mass.

5) Trajectory robustness:

Can an algorithm be designed to handle the atmospheric and aerodynamic uncertainties associated with aerocapture? Better atmospheric uncertainties are needed and credible aerodynamic uncertainties need to be estimated for ballute configurations. Probabilistic methods need to be used in trajectory design.

6) Structural integrity:

Even though dynamic pressure and heating is low compared to rigid aeroshells, ballute materials are more fragile to achieve mass benefits. Can a ballute designed out of light weight materials handle the large drag forces?

7) Tether design:

Can tethers handle the high heat rate due to their small radius relative to the ballute? Issues such as shock impingement from the spacecraft and attachment to the ballute need to be resolved.
8) Parent spacecraft protection:

Ballutes have large nose radii to reduce heating. The spacecraft is relatively small, so heat rates are higher. Does the spacecraft need thermal protection, and how do you protect deployables?

9) Deployment and inflation:

Deployment technology can be borrowed from the Inflatable Antenna Experiment [43], but additional work needs to be done to avoid tether tangling. The inflation system also needs a mechanism to avoid overpressure as the gas expands during the atmospheric pass.

10) Experimental verification:

For planetary missions the complete aerothermodynamic environment cannot be reproduced on Earth. What combination of testing and analysis is sufficient to prove the concept? Can the appropriate scaling parameters be matched for testing?

The remainder of this paper will survey the technology applicable to the ballute aerocapture problem. The majority of studies reviewed have been published since 2000 , but some that seem particularly relevant are from earlier dates. The work has been separated into sections on trajectory analysis, structural analysis, hypersonic aerothermodynamics, coupled analysis, and flight tests.

\section{TRAJECTORY ANALYSIS}

During 2003 and 2004 a significant amount of work was performed to determine the aerocapture capability of ballutes at Titan. Miller et al performed a systems study based on the toroidal trailing ballute. Ref. [44] details the analysis, including configuration and spacecraft packaging, aeroheating in the continuum, transitional, and free molecular flight regimes, thermal, and trajectory analyses. An aerodynamic database was developed for a 5:1 (R/r) torus and was used for trajectory analysis. Titan atmospheric entry was initiated at $1000 \mathrm{~km}$ altitude, at $6.5 \mathrm{~km} / \mathrm{s}$ velocity, typical of a low-thrust trajectory to the Saturnian system. For comparison, Mars aerocapture trajectories were also investigated, with a nominal $5.5 \mathrm{~km} / \mathrm{s}$ velocity at 200 $\mathrm{km}$ altitude. For Titan and Mars, $\beta$ was 0.4 and 0.8 $\mathrm{kg} / \mathrm{m}^{2}$ respectively. Table 1 lists the critical points in the trajectory for both Mars and Titan aerocapture. Titan trajectory work was extended to include an algorithm for ballute release. The algorithm uses orbital energy as the release criteria and propagates the trajectory onboard using accelerometer data and an updated density model. A Monte Carlo analysis was performed with perturbations to the atmosphere, accelerometer data, 
entry velocity, entry flight path angle, and $\beta$. The resulting circularization velocity increment and heating values are presented in Table 2. Two other sources [45, 46] have implemented algorithms for ballute release at Titan and performed Monte Carlo analysis showing similar performance.

Table 1. Comparison of Mars and Titan aerocapture trajectories [44].

\begin{tabular}{lcc}
\hline & Mars & Titan \\
\cline { 2 - 3 } Ballute $\beta\left(\mathrm{kg} / \mathrm{m}^{2}\right)$ & 0.8 & 0.4 \\
$\beta_{\text {spacecraft }} \beta_{\text {ballute }}$ & 140 & 145 \\
$\mathrm{~V}_{\text {entry }}(\mathrm{km} / \mathrm{s})$ & $5-6$ & $6-8$ \\
Pass duration $(\mathrm{s})$ & 1100 & 3600 \\
Velocity decrement $(\mathrm{km} / \mathrm{s})$ & 2.0 & 4.8 \\
Peak deceleration $(\mathrm{g}$ 's) & 2.8 & 4.3 \\
Peak heat rate $\left(\mathrm{W} / \mathrm{cm}^{2}\right)$ & 2 & 0.9 \\
Peak dynamic pressure $(\mathrm{Pa})$ & 28 & 46 \\
\hline
\end{tabular}

Table 2. Results of Monte Carlo simulation of Titan aerocapture trajectory [44].

\begin{tabular}{lc} 
Number of failed* cases $^{*}$ & 0 \\
Min. Circularization $\Delta \mathrm{V}$ & $125 \mathrm{~m} / \mathrm{s}$ \\
Max Circularization $\Delta \mathrm{V}$ & $376 \mathrm{~m} / \mathrm{s}$ \\
Mean Circularization $\Delta \mathrm{V}$ & $186 \mathrm{~m} / \mathrm{s}$ \\
Mean + 3- $\sigma$ Circularization $\Delta \mathrm{V}$ & $285 \mathrm{~m} / \mathrm{s}$ \\
Mean heat rate & $1.9 \mathrm{~W} / \mathrm{cm}^{2}$ \\
Mean + 3- $\sigma$ heat rate & $2.1 \mathrm{~W} / \mathrm{cm}^{2}$ \\
\hline * Failure is entering, or not capturing. &
\end{tabular}

In [47], Lyons and Johnson studied the trailing toroidal ballute for Neptune aerocapture into a highly eccentric orbit with apoapsis at $430,000 \mathrm{~km}$. This study was aimed at sizing a ballute for a $500 \mathrm{~kg}$ spacecraft. Three ballute sizes $\left(750,1477,3000 \mathrm{~m}^{2}\right)$ and seven entry velocities $(22.4,22.8,23.4,24.1,25.0,26.1,27.2 \mathrm{~km} / \mathrm{s})$ were explored. Fig. 8 shows the maximum heat rate on the ballute for the range of entry velocities. Peak heat rate varied by roughly a factor of 2 for different ballute areas, with larger ballutes at lower entry speeds being advantageous from a heating perspective. Trajectories in this study were targeted independently such that the exit conditions were met without releasing the ballute. Because this method did not account for uncertainties, the heat rates shown would increase once a lower periapsis is targeted to account for uncertainties. Peak deceleration is shown to be $3.5 \mathrm{~g}$ 's, but again will increase slightly once uncertainties are accounted for. Even if the deceleration increased by $40 \%$, the acceleration would still be less than $5 \mathrm{~g}$ 's, a tolerable level for instruments and even humans. The study concludes that heat rate is the driving factor in ballute design for Neptune entry given the high entry velocities. An effort should be made to design a mission which reduces the arrival velocity so that heat rate can be maintained within the limits of thin-film materials for reasonable size ballutes.

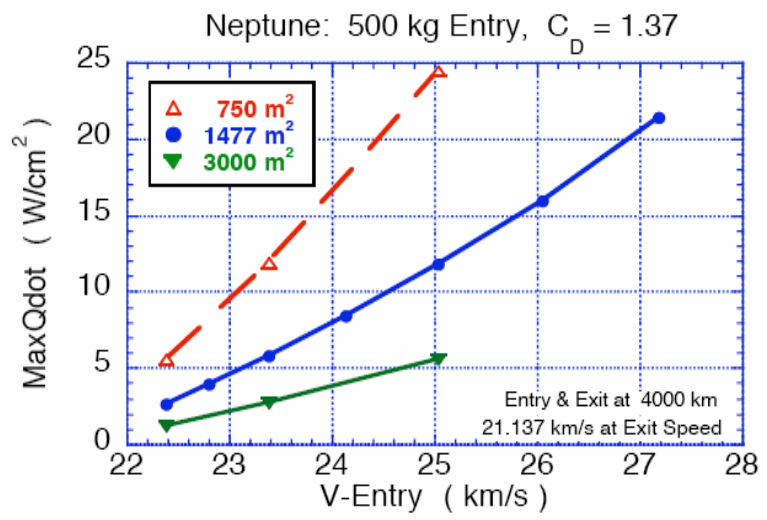

Figure 8. Peak heat rate on a trailing toroidal ballute at Neptune [47].

Ballute aerocapture trajectories have been explored thoroughly for a $500 \mathrm{~kg}$ spacecraft at Titan. A robust algorithm has been developed that successfully inserts the spacecraft into orbit using drag modulation while accounting for uncertainties. Preliminary analysis at Neptune and Mars is also presented and shows that a sufficient entry corridor exists to account for uncertainties. The algorithm presented in [44] needs to be adapted to other atmospheres, or new ones developed, to verify the ability to perform ballute drag-modulated aerocapture at other planets.

\section{STRUCTURAL ANALYSIS}

Structural analysis of early inflatables was largely based on empirical results and application of simple membrane equations. In 1964, the membrane equations were manipulated by Houtz to show that a uniform stress fabric reinforced with meridian cords could be designed for a given axially symmetric pressure load. In [48], he shows the technique by which the meridian profile, number of meridian cords, and fabric gore shape could be designed using algebra and integration. The solutions are families of curves dependent on the axial load factor $(\rho)$ and meridian cord factor $(k)$. When $\rho=0$ the solution has zero slope at the axis, and when $k=0$ too, the surface becomes a sphere with uniform stress in all directions. When $\rho=0$ and $k=1$ the stress is carried completely in the meridians. These two cases are the bounding curves in Fig. 9 for a constant pressure load which is typically used for aft surfaces. For forward surfaces, the pressure distribution is fixed and the surface shape must be solved. Though not stated in the paper, it would clearly be necessary to iterate between the actual shape obtained and the pressure distribution to achieve a consistent solution. This method became 
the de facto method for ballute design in the later half of the 1960's.

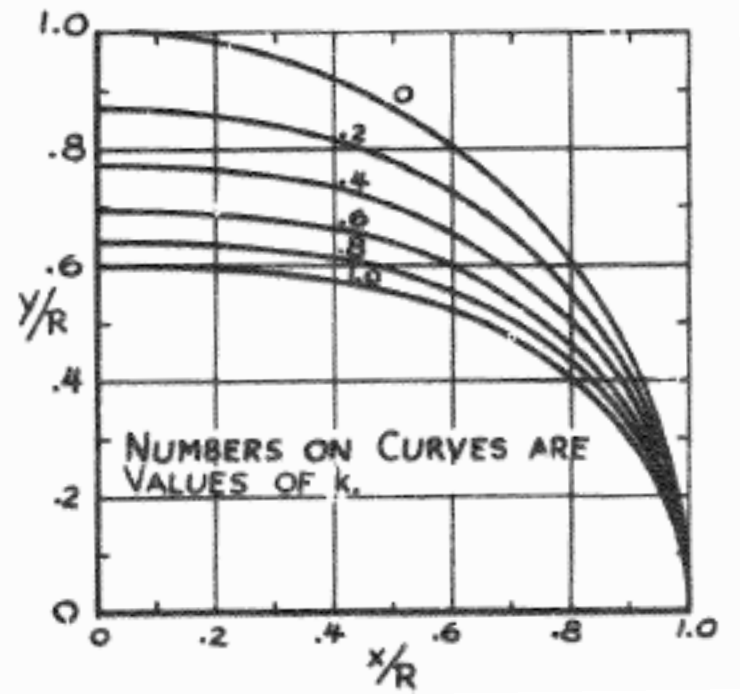

Figure 9. Surface curves for $\rho=0$ and constant pressure load [48]. The $y$-axis is the axis of symmetry and $r$ is the base radius.

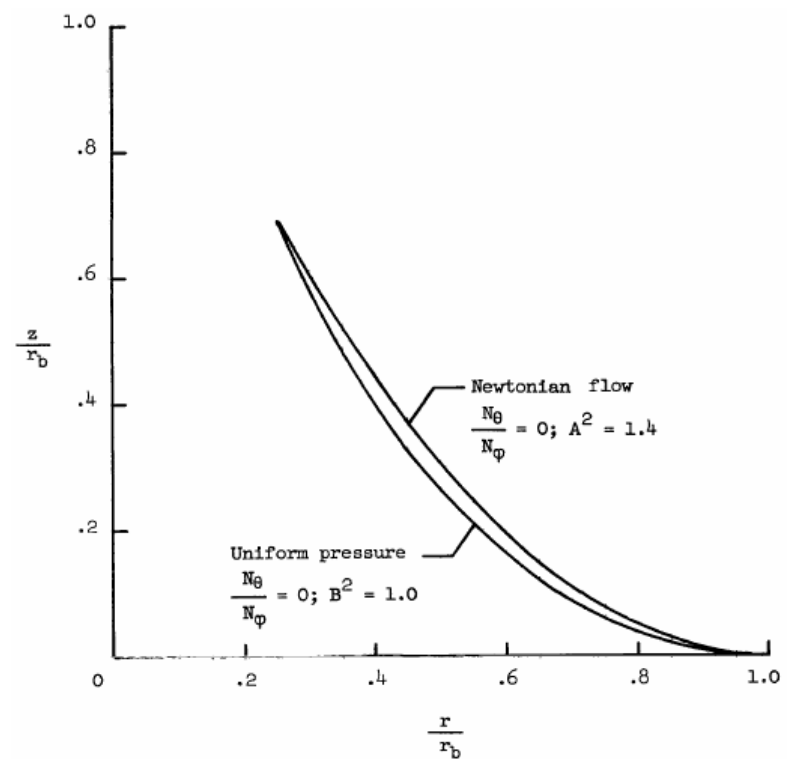

Figure 10. Tension shell surface shapes for Newtonian and constant pressure distributions. The $z$-axis is the axis of symmetry and $r_{b}$ is the base radius. A spherical nose fills the gap between $r / r_{b}=0$ and 0.2 , and flow is from top to bottom [50].

Also in 1964, Anderson identifies that aeroshell design is limited by the buckling load case, so the full strength of materials is not utilized [49]. This led to the concept of the tension shell entry vehicle where the compressive load is isolated in a single ring structure at the base of the vehicle. Anderson also demonstrates that the tension shell shape can achieve a lower ballistic coefficient than a rigid aeroshell. In [50] the shape is mathematically defined using membrane theory and both a constant and Newtonian pressure loading. The surface contours for each pressure loading are shown in Fig. 10 for solutions with the same end points. The small difference in the contours indicates that the shape is not sensitive to the pressure distribution since the Newtonian and constant pressure distributions are quite different. From the pressure distribution it was found that for relatively blunt versions of the tension cone the drag coefficient was between 1.4 and 1.7.

Since the tension shell required no compressive strength, a thin fabric or membrane could be used as the aerodynamic surface. To achieve very low ballistic coefficients the surface could be deployed using an inflatable torus to support the compression load. In 1967, the equations for buckling of a radially loaded pressurized toroidal shell were developed [51]. These equations were then verified and used in [52] to analyze the deployment and flight of a tension cone. For verification purposes two fixtures were used to apply a distributed radial load to the torus: a toggle harness, and a vacuum bag apparatus. Both a slender $(R / r=7.25)$ and a stout torus $(R / r=4.71)$ were tested in each fixture, and three compressive failure modes were identified. The first failure mode is when the circumferential load in the torus due to the radial load $(P)$ exceeds the circumferential force in the torus due to pressure:

$$
P>p \pi r^{2}
$$

where $p$ is the fill pressure, and $r$ is the minor radius of the torus. This mode was termed the crippling mode and was characterized by a wrinkling of the torus surface followed by the torus folding, out-of-plane, about a single hinge line. The remaining two failure modes are in-plane and out-of-plane buckling modes. The out-ofplane buckling mode appeared as a curling deformation and was able to support an increasing load until the crippling load was reached. The in-plane buckling mode appeared as four hinges and four arcs as shown in Fig. 11. The buckling load as a function of internal pressure for the slender torus, shown in Fig. 12, is in good agreement with theory. For the stout torus the results are similar, except that the wall has a larger contribution to the compressive strength, hence collapse is observed consistently at loads greater than the crippling load. 


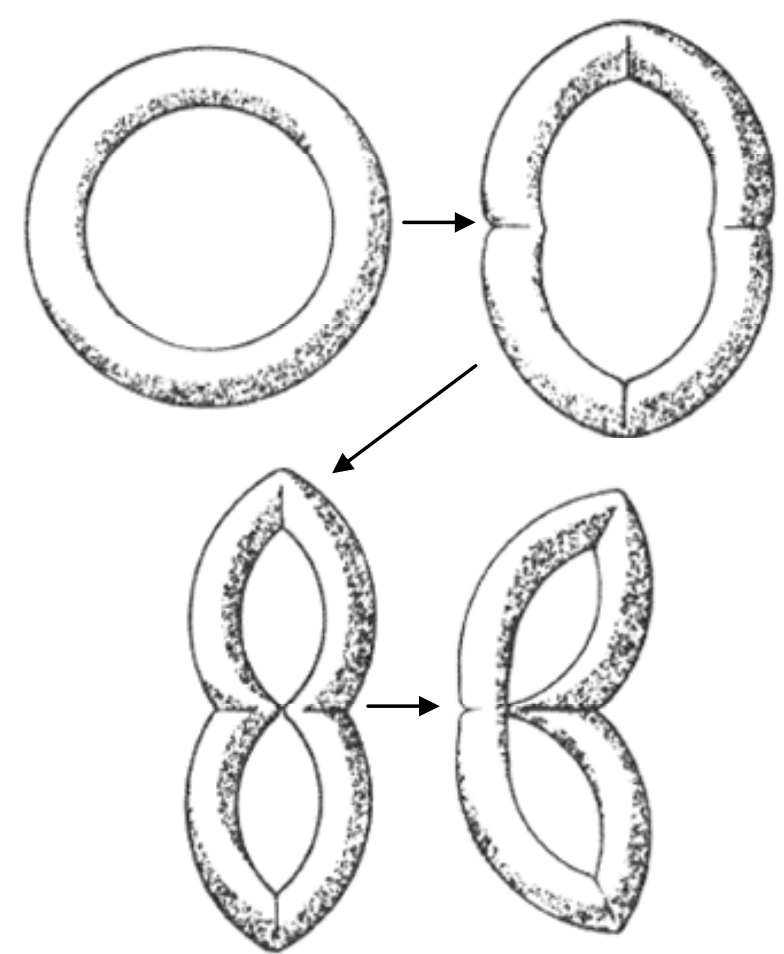

Figure 11. Planar buckling mode of a pressurized toroidal shell under uniform radial load [52].

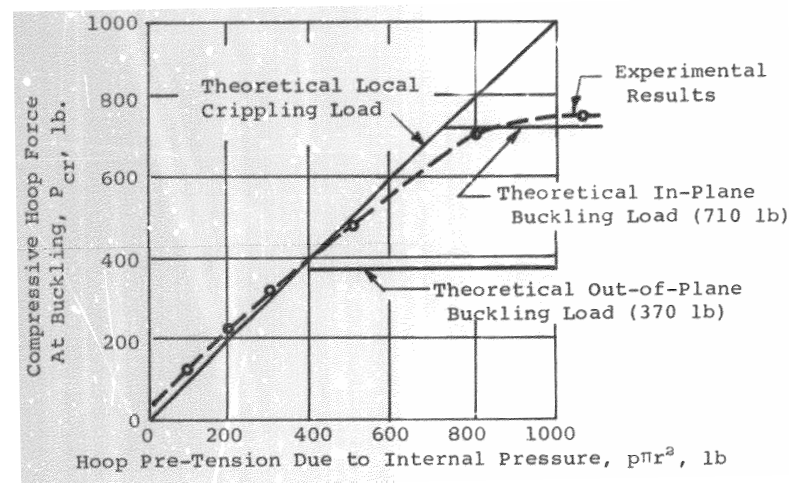

Figure 12. Buckling load as a function of internal pressure for a slender torus. Good agreement between experiment and theory is observed [52].

Ref. [52] also developed a model for deployment of an inflated torus based on a hinge moment when the torus is folded, out-of-plane, in half. The model was applied to a tension shell decelerator and tested in a water tow tank. Results indicated that the theory is conservative as complete deployment was observed at lower fill pressures and higher dynamic pressures than predicted. It should also be noted that the surface shape was designed using a Newtonian pressure distribution and produced wrinkles during tow tests, indicating that the actual pressure distribution was far from Newtonian.

In recent years finite element analysis (FEA) has been used to analyze ballutes. Ref. [53] details the analysis of a coated fabric clamped ballute with TPS using FEA. The LS-DYNA structural dynamics code is used to study the deformation due to aerodynamic pressure and the effect air chamber deflation on two different configurations. The analysis utilized the fabric material and inflation models developed for automotive airbag analysis.

The NASTRAN and ABAQUS codes were also used to model an inflated cylindrical membrane strut. Modal analysis was performed using each analysis package and the results compared favourably to experiment for the first mode. For higher modes results were not as good, with errors as high as $24 \%$. Within the results for the first mode, better accuracy was achieved for stiffer configurations (thicker membrane and higher inflation pressure). In general the NASTRAN and ABAQUS codes were found to have similar accuracy.

Numerical modelling of thin polymer membranes has presented several difficulties including numerical instability and accurate capture of surface wrinkles and deformation. Many of the membrane modelling advances have been made by the solar sail community and are only just starting to be applied to ballutes. In [54], Wang et al use the ABAQUS code to explore the effects of element formulation and analysis type (implicit vs. explicit) on the deformation of a membrane strip under gravity loading. This seemingly simple problem is proves difficult to solve numerically. The implicit solution technique only produced correct results for the membrane element formulation with either stabilization or pre-tension added. Only reduced integration shell elements were able to produce converged solutions, though the results under-predicted the deformation. The explicit solution technique used a reduced integration shell element and produced the correct result with artificial damping added to eliminate oscillations due to the load application method.

The numerical prediction of surface wrinkle amplitudes in a true membrane is not possible due to the influence of bending and compressive stiffness on the shape of the wrinkles. Furthermore, initially flat membranes under shear or compression will not buckle because there is no means to produce a bending moment. This problem was resolved by initially perturbing the nodes by a fraction of the membrane thickness to couple the bending moment to the shear and compressive loads 
[55]. The method was used to predict wrinkles in a flat membrane subject to a pure shear load and a flat membrane subject to corner tension. The wrinkle patters in the computational results compare well with experiments, but the amplitudes vary by nearly a factor of 2. Ref. [56] applies the tension field theory to predict the wrinkle patterns, and nonlinear post-buckling analysis to predict the wrinkle amplitudes in a square membrane with corner loads. Amplitude prediction is quite good for wrinkles away from the edges, but wrinkle amplitudes near the edges are much smaller than those found in testing.

Theories have been developed and validated through tests for pressure stabilized structures in the presence of variable external loads. The analytical methods presented provide the tools for preliminary sizing of both clamped and trailing ballutes. The finite element method has been successfully applied to analysis of coated fabric ballutes and modelling of thin polymer membranes should be possible due to advances made by the solar sail community.

\section{HYPERSONIC AEROTHERMODYNAMICS}

Unsteady flow effects have long been observed in parachutes and so it was not surprising to see them in early supersonic ballute tests. McShera and Keyes observed time varying flow separation from the tow cable in [9], and McShera observed failure due to unsteady flow in [11].

Early tests were at supersonic Mach numbers with relatively high dynamic pressures (at low altitude on Earth). In contrast, aerocapture applications encounter only hypersonic flow, and low dynamic pressures [57] $(q<100 \mathrm{~Pa}$ compared to $q>12 \mathrm{kPa})$, but may still suffer failure due to a fluctuating thermal environment or fluid-structure interaction. Computational and experimental studies of ballute aerodynamics have been performed as a series of related studies, with overlapping cases for validation purposes.

\subsection{Experimental Results}

Rasheed, Fujii, Hornung, and Hall [58] performed a set of experimental studies using a toroidal ballute. It was thought that the hole in the torus would swallow the spacecraft wake and reduce aerodynamic interaction between the bodies. Due to the resulting small minor radius of the torus, heating was a concern and testing was performed to determine the heating rate on the torus. Heating tests were performed in the Graduate Aeronautical Laboratories, California Institute of
Technology (GALCIT) T5 Hypervelocity Shock Tunnel. Test conditions were set to match Reynolds number and enthalpy similarity criteria for aerocapture of the Mars Micro Satellite and the Titan Organics Explorer, two possible applications of a toroidal ballute. Table 3 shows the design parameters for these two missions. Test results show good agreement with theory for the Stanton number as a function of Reynolds number which can be extrapolated to provide heat rates for these missions. Additional tests were performed with the hole of the torus blocked to verify the unsteadiness observed in the computational results of [60]. The complex shock shape shown in the experiment indicates the flow was unsteady.

Table 3. Ballute mission design parameters [58].

\begin{tabular}{lcc}
\hline & $\begin{array}{c}\text { Mars Micro } \\
\text { Satellite }\end{array}$ & $\begin{array}{c}\text { Titan Organics } \\
\text { Explorer }\end{array}$ \\
\cline { 2 - 3 } $\mathrm{D}_{\text {major }}(\mathrm{m})$ & 15 & 52 \\
$\mathrm{D}_{\text {minor }}(\mathrm{m})$ & 3 & 13 \\
$\mathrm{~V}_{\infty}(\mathrm{m} / \mathrm{s})$ & 5490 & 8550 \\
$\rho_{\infty}(\mathrm{kg} / \mathrm{m} 3)$ & $7.1 \times 10^{-7}$ & $1.9 \times 10^{-7}$ \\
$\mathrm{Gas}$ & $95 \% \mathrm{CO}_{2}$ & $98 \% \mathrm{~N}_{2}$ \\
\hline
\end{tabular}

McIntyre et al extended the work of [58] to flows of higher freestream enthalpy to better capture the effects of dissociation and ionization in [59]. A moderate enthalpy case $(\sim 18 \mathrm{MJ} / \mathrm{kg})$ in $\mathrm{CO}_{2}$ and $\mathrm{N}_{2}$ was studied for comparison to the previous study, and a high enthalpy case $(\sim 50 \mathrm{MJ} / \mathrm{kg})$ was studied to see the effects of dissociation and ionization. Additional testing was performed at high enthalpy $(\sim 80 \mathrm{MJ} / \mathrm{kg})$ in a HydrogenNeon gas to simulate entry into a gas giant. The toroidal ballute model used in [58] was scaled to fit in the University of Queensland superorbital expansion tube, $\mathrm{X} 2$. Both a standard torus and a blocked torus model were used to explore the effects of choked flow. In general, it was found that shock interaction occurs further downstream for higher enthalpy and higher Mach number flows. Good agreement between calculated and experimental heat rate was observed for the moderate and high enthalpy $\mathrm{N}_{2}$ conditions and the high enthalpy $\mathrm{CO}_{2}$ condition. The flow around the blocked torus was unsteady in all conditions. Table 4 shows a sample of the experimental data obtained and the calculated heat rate and Stanton number for the moderate enthalpy $\mathrm{N}_{2}$ case. When higher freestream enthalpies were included it was found that the Stanton number still followed the $R e^{-1 / 2}$ relation found in [58]. 
Table 4. Measured and calculated results for moderate enthalpy flow in $\mathrm{N}_{2}[59]$.

\begin{tabular}{cccccc}
\hline & & $\begin{array}{c}\text { Exp. } \\
\text { heat } \\
\text { rate, } \pm 3\end{array}$ & \multicolumn{3}{c}{$\begin{array}{c}\text { Theory } \\
\text { heat } \\
\text { Exp. St }\end{array}$} \\
Shot \\
rate, \\
C1 & 2090 & 24 & $10 \times 10^{-3}$ & 24 & $10.1 \times 10^{-3}$ \\
C2 & 2800 & 27 & $9.3 \times 10^{-3}$ & 26.3 & $9.06 \times 10^{-3}$ \\
C3 & 2800 & 25 & $8.6 \times 10^{-3}$ & 26.3 & $9.06 \times 10^{-3}$ \\
C4 & 2800 & 19 & $6.5 \times 10^{-3}$ & 26.3 & $9.06 \times 10^{-3}$ \\
\hline
\end{tabular}

\subsection{Computational Studies}

In 2001, Hornung [60] performed a series of timeaccurate inviscid CFD solutions for vehicles with an elliptical and a toroidal towed ballute. The study examined the effect of towing distance and a sting support. The elliptical trailing body was found to have violently unsteady flow for medium towing distances, but steady flow for very short or very long towing distances. Fig. 13 shows a pseudo-schlieren image at Mach 10 for an elliptical towed ballute at medium distance with unsteady shock structure. Since the unsteadiness in the flow originated from interaction of the towing spacecraft wake with the shock structure of the towed ballute, it was thought that moving the shock interaction further downstream from the spacecraft would improve the situation. By using a toroidal ballute the towing distance could still be reasonable, and the shock interaction would be moved downstream because it would pass through the hole in the torus. Further computations showed that the spacecraft wake was swallowed, but the shock reflections on the axis of symmetry produced such high pressure that the shock moved upstream to the base of the towing spacecraft, producing unsteady flow in its wake. The addition of a sting supporting the spacecraft significantly reduces unsteadiness and leads to a much more benign environment for the spacecraft.

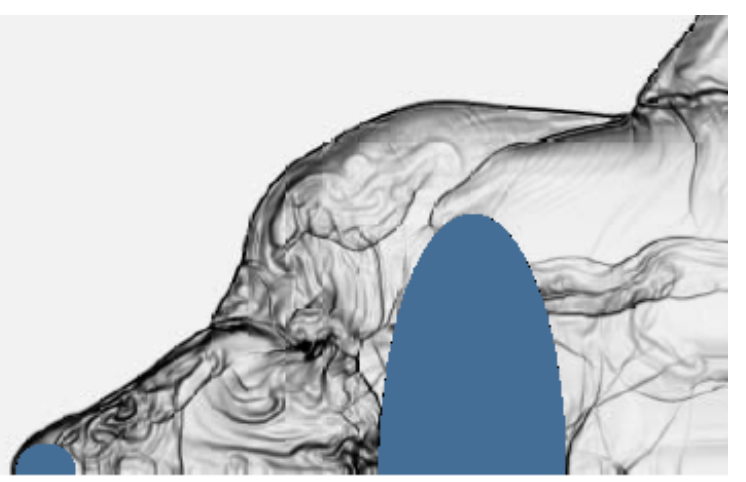

Figure 13. Elliptical towed ballute at medium distance, Mach 10 flow, and unsteady shock structure [60].
Since the torus must be connected to the spacecraft with a tension device, it would be convenient to counter the radial force of the tethers with outward lift from the torus. This can be accomplished by giving the torus an elliptical cross section with an angle of attack. Analysis of this configuration yielded the steady shock structure shown in Fig. 14. The effectiveness of a ballute can be based on the mass required to achieve equivalent drag. Analysis of the elliptical and toroidal ballutes shows that the primary difference is in the inflation gas, with the toroidal ballute requiring about $1 / 4$ the volume of the elliptical ballute.

Computational studies using the LAURA [ 61 ] algorithm were preformed in [62] for one of the toroidal ballute cases (torus only) at Mars used in [58] (case T2018-toroid) to validate the computed heating rate. The computational models include viscous and real-gas effects [63]. Three different boundary conditions were analyzed with the experimental data being bounded by the fully catalytic wall and the fully catalyzed atomic oxygen only cases, except near $\theta=90^{\circ}$. Fig. 15 shows the experimental data along with the three computed heating rates. Drag coefficients for toroidal and spherical ballutes are also calculated in the Venus, Saturn, Titan, and Neptune atmospheres.

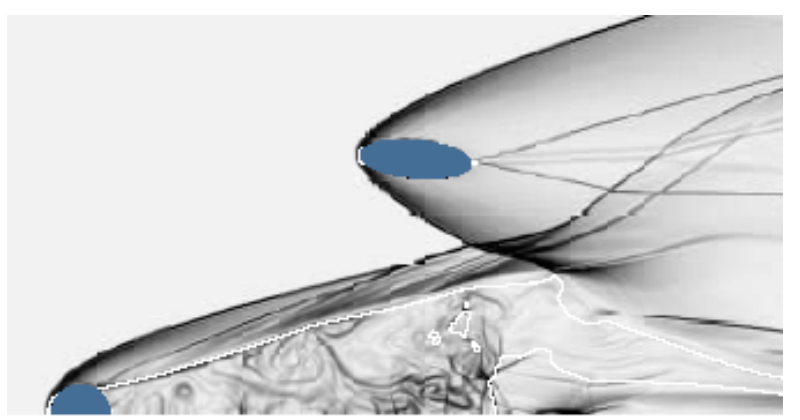

Figure 14. Steady flow over a sphere towing a toroidal ballute with elliptic cross section at an angle of attack to counter the radial tether forces [60].

Additional computational studies of toroidal and spherical trailing ballutes were performed by Gnoffo and Anderson in [64] using the LAURA algorithm in the Titan atmosphere. Studies of a trailing toroidal ballute found that a steady solution exists with no flow impingement on the aft of the spacecraft. The same model run with an increased Reynolds number produced a much stronger interaction which enveloped the base of the spacecraft as in [60], but the solution had only small oscillations present near the base of the spacecraft. Even with flow impinging on the aft end of the spacecraft there was no unsteady flow interaction 
with the ballute. The increased heat rate on the spacecraft could easily be countered by addition of thermal protection to the spacecraft backshell.

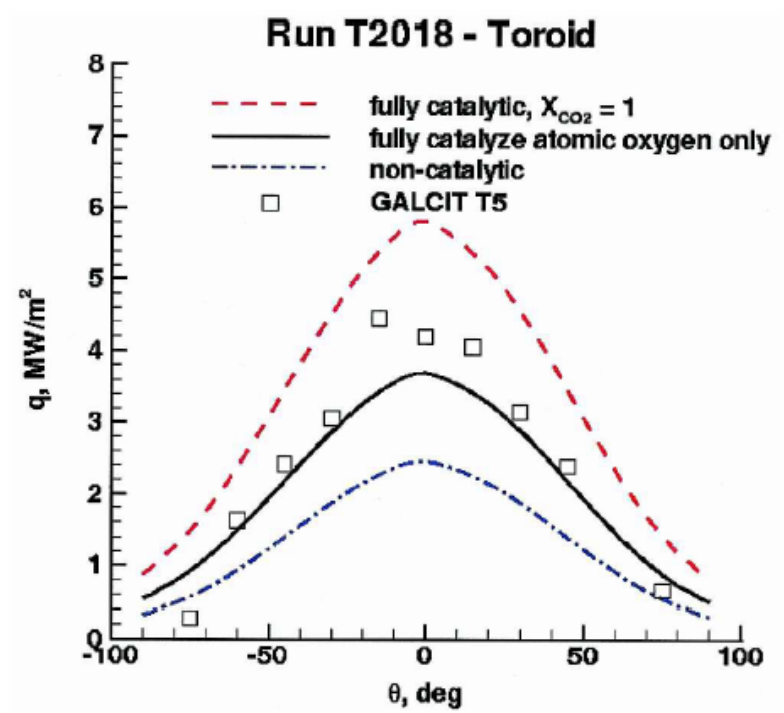

Figure 15. Heat transfer on the wall of a toroidal ballute in $\mathrm{CO}_{2}$ computed by LAURA and measured in the California Institute of Technology T5 shock tunnel [62].

For the trailing spherical ballute studies, the same $6 \mathrm{~m}$ diameter spacecraft was used, and a $70 \mathrm{~m}$ diameter sphere was towed at distances ranging from $0 \mathrm{~m}$ to 200 $\mathrm{m}(0,30,40,50,100,200 \mathrm{~m})$. For towing distances between 30 and $200 \mathrm{~m}$ the peak drag produced by the ballute occurs at a tow line length near $50 \mathrm{~m}$. For the longer towing distances the ballute is almost completely enveloped in the low dynamic pressure of the spacecraft wake, producing significantly less drag. In this distance range there is a significant increase in heat rate on the ballute where the spacecraft bow shock intersects the sphere bow shock. In all computational cases a steady state flow resulted for the baseline conditions, and a recirculation zone was present in front of the sphere for tow distances between 30 and $100 \mathrm{~m}$. As with the toroidal ballute, a ten fold increase in Reynolds number produced marginally unsteady flow with upstream flow extending to the base of the spacecraft for the $40 \mathrm{~m}$ towing distance, similar to that observed for elliptical ballutes in [60]. For the limiting case of zero tow distance the spacecraft is protected within the shock layer of the ballute, resulting in lower heat rates.

Fig. 16 compares the convective heating rate on the clamped ballute configuration to the sphere and spacecraft individually. The lack of shock interactions, unsteady flow, and reduced heating rates make this an attractive option. In the analysis of both the toroidal and spherical ballutes the wake flow had a Knudsen number of order 1 or higher, invalidating the continuum solution. Future work needs to include a mixed continuum and transitional regime solution in these areas.

In 2004 Anderson studies the static stability and effects of transitional flow on a spherical, clamped ballute [65]. Static stability was determined from a threedimensional continuum solution at $5^{\circ}$ angle of attack. It was found that the clamped ballute was statically stable $\left(\frac{\partial C_{m}}{\partial \alpha}<0\right)$. The effects of transitional flow on the ballute were determined by using a direct simulation Monte Carlo (DSMC) solution. The resulting heat rate falls between the continuum solution for a perfect gas with $\gamma=1.2$ and a thermal non-equilibrium gas with $\gamma=$ 1.4, and is shown in Fig. 17.

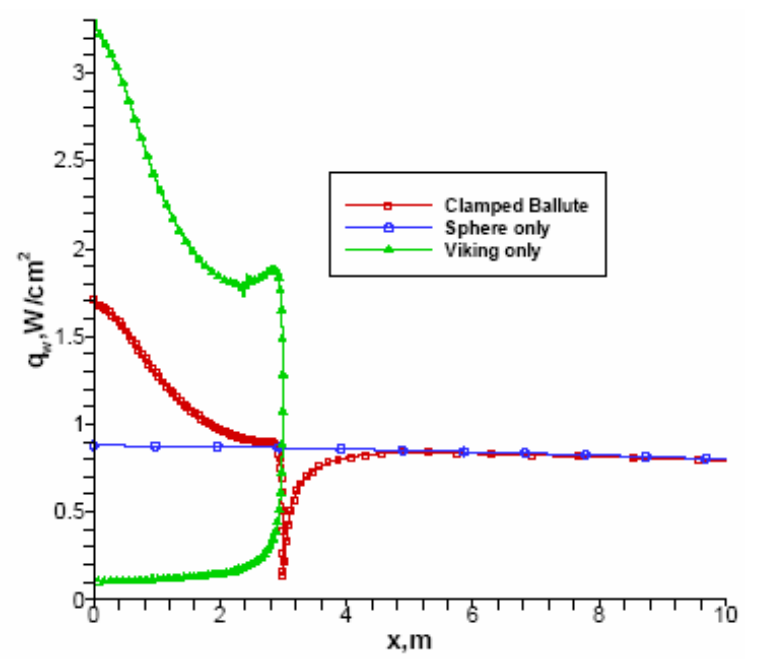

Figure 16. Heat rate on the towed sphere and spacecraft independently compared to the clamped ballute [64].

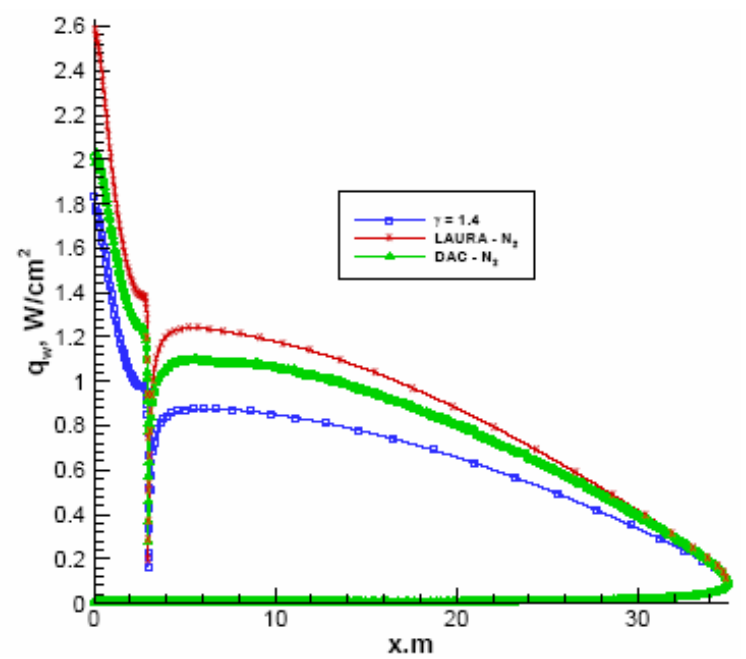

Figure 17. Effects of transitional flow on the surface heat rate to a clamped ballute [65]. 
The premise of achieving lower system mass thru increased size, lower $\beta$, and lower heat rate is questioned by Park in [66]. He points out that radiative heating has not been considered, and while convective heat rate decreases with increasing size, radiative heat rate is proportional to shock stand-off distance, and so increases with vehicle size. Park reviews the radiative heat rate observed in ground and flight tests and the theories for predicting radiative heat rate. Using the best theory available (in 1987), the radiative heat rate for Earth return from Geosynchronous Earth orbit ranges from $2.5 \mathrm{~W} / \mathrm{cm}^{2}$ to $7.0 \mathrm{~W} / \mathrm{cm}^{2}$ for nose radii of 3 and 12 $\mathrm{m}$ respectively, with the rate increasing by a factor of 2.4 for lunar return. This level of heat rate input would be problematic for many candidate ballute materials and would drive the system to larger diameters. Clearly, additional work is needed to determine radiative heat rate for the Earth and other atmospheres and these effects must be factored into ballute systems design.

The work done in the area of hypersonic aerothermodynamics has shown that unsteady flow exists for simple (spherical and elliptical) trailing ballutes, but can be avoided by using a toroidal trailing ballute at low Reynolds numbers or a clamped ballute. Testing has verified the convective heat rate predictions of the computational methods currently in use. Estimation of radiative heat transfer at high altitudes and for non-terrestrial atmospheres remains a major issue. Further work is necessary to determine the effects of rarefied and transitional flow in the wake of trailing ballutes and at higher altitudes.

\section{COUPLED ANALYSIS}

Recognizing that structural shape and aerodynamics are coupled, Park simplified the ballute to a twodimensional problem and found a differential equation subject to constraints that defined its shape [67]. This set of equations were integrated numerically for a given angle of attack, ballute geometry, internal pressure, and material elasticity to find the aerodynamic parameters. This approach enabled Park to study the possibility of using internal pressure to control drag. Fig. 18 shows the variation in drag coefficient as a function of the overpressure parameter $(\Delta)$ and pressure to elasticity ratio $(x)$.

$$
\begin{gathered}
\Delta=\frac{p}{\rho U^{2}}-1 \\
x=\frac{L_{0}}{\phi} U^{2}(1+\Delta)
\end{gathered}
$$

where $p$ is the internal pressure, $U$ is the freestream velocity, $\rho$ is the freestream density, $L_{0}$ is the rigid vehicle length, and $\varphi$ is the membrane elastic constant
$(\mathrm{N} / \mathrm{m})$. For small values of $x$, the membrane stiffness dominates, and there is little change in the ballute drag, but for $x=1 \mathrm{drag}$ varies by a factor of 5. Therefore $x$ must be of order 1 or greater to use internal pressure to control ballute drag.

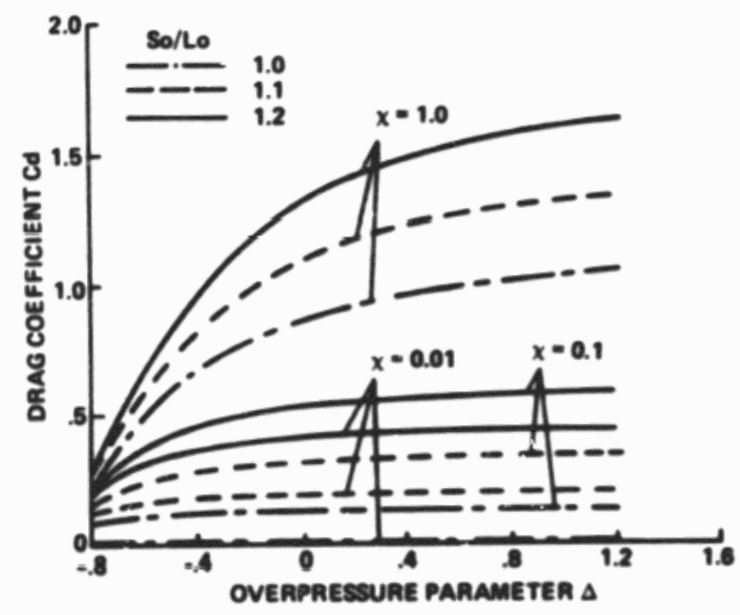

Figure 18. Variation in $C_{D}$ as a function of $\Delta$ and $x$ at $0^{\circ}$ angle of attack [67].

An aerocapture trajectory was calculated using planar translational degrees of freedom and one rotational degree of freedom. The trajectory was run with the center of gravity (CG) at $0.3000,0.4375$, and 0.4438 times the vehicle length and a small initial angle of attack. The two cases with the CG closest to the nose were stable, but the case with $C G=0.4438 * L_{0}$ became unstable and started to tumble in the low density atmosphere. For stability at all freestream densities the CG must be less than $0.18 * L_{0}$. This is a very restrictive CG location, but subsequent trajectory work showed that the ballute's dynamic motion was bounded up to $\mathrm{CG}=0.4375 * L_{0}$ since the relatively short time spent in the low density region of the atmosphere does not allow the aerodynamic instability to propagate significantly.

With the advent of numerical solutions to the NavierStokes equations and the increase in computer speed in the late 1970's and early 1980's, the use of computational fluid dynamics (CFD) emerged. Ref. [68] used CFD to iteratively determine the surface shape of a tension shell vehicle. For this study, an axisymmetric CFD solution was used to determine the pressure distribution. The pressure distributions showed good agreement with experimental results, but poor agreement with Newtonian theory at Mach 7. The discrepancy is due, in part, to separated flow for models with large nose radius relative to base radius, which Newtonian theory cannot capture. The iterative method used to achieve a consistent solution converged in less 
than 4 iterations and consistently produced a shorter (more blunt) shape than the initial guess using a uniform pressure distribution. Fig. 19 shows a representative example of the surface pressure and shape after each iteration.

The next major advance in modeling of ballutes was the time accurate coupling of computational structural dynamics (CSD) and CFD. Ref. [69] presents a coupled solution for the deployment of a trailing ballute at Mach 2 and its final shape using the MONSTR code. The MONSTR code combines a fabric shell structural dynamic solution with three different continuum flow solvers capable of handling moving boundaries. The technology is applicable to any thin, flexible body and [70] compares the numerical solution for surface pressure and aerodynamic coefficients to experimental data for several parachutes and a supersonic ballute. The results are quite accurate for the subsonic and low supersonic flight regimes examined. While the code appears capable of transient solutions, the flight condition was fixed for the analysis presented.

Aeroelastic analysis of ballutes poses many challenges, including: 1) coupling of a highly flexible structure, 2) nonlinear fluid and structure behaviour, 3) FEA of highly nonlinear membranes, and 4) experimental validation of results [71]. Bartels et al propose wind tunnel tests utilizing the NASA Langley Transonic Dynamics Tunnel to explore the effects of model scale and construction techniques and a computational effort. The computational effort will focus on coupling a nonlinear FEA code to a hypersonic aerothermodynamic code using loose coupling for static solutions and closely coupled modal methods for dynamic solutions. Due to large computational requirements, system identification and order reduction are suggested when possible. This computational aeroelasticity technique was recently demonstrated for a generic launch vehicle in hypersonic flight [72].

Coupled CSD and CFD codes represent a significant advance in modeling of inflatable decelerators, but still lack the ability to find solutions for aerocapture trajectories where flight conditions are in the transitional and free-molecular regimes, and when realgas effects are important. Many challenges to ballute aeroelastic analysis have been identified and a plan is proposed to overcome them. Ongoing work in this area is described further in Section 8 of this paper. The complete simulation package would also include coupling to thermal and trajectory analyses so that performance and integrity of the complete system could be evaluated in a fully coupled manner.
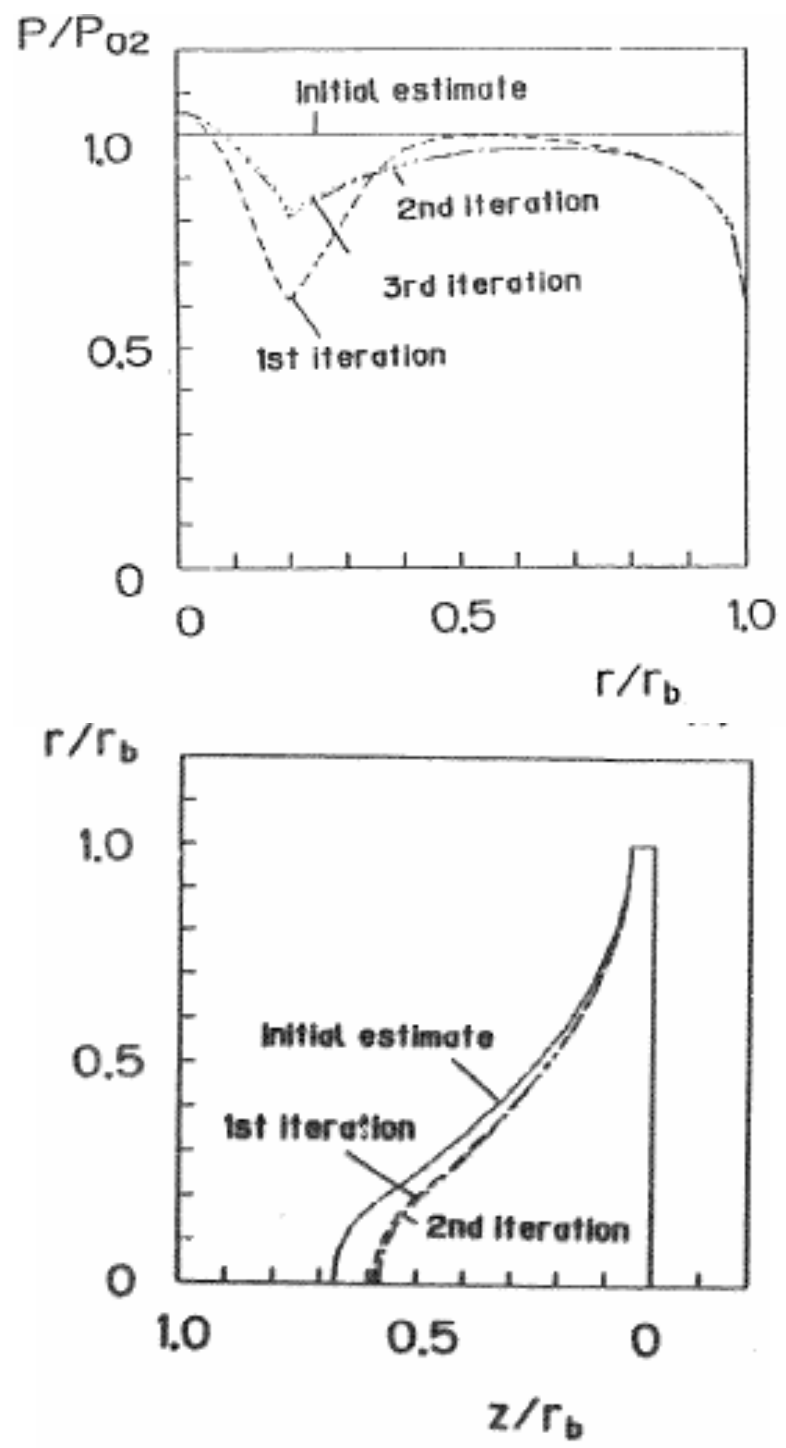

Figure 19. Iteration history of pressure distribution (a) and vehicle shape (b) for a consistent tension shell vehicle [68].

\section{FLIGHT TESTING}

At the time of this writing (June 2005) no ballute has successfully been flight tested in aerocapture relevant conditions. Successful ballute tests have been achieved for subsonic and supersonic applications [73, 74, 75, and 76]. Three attempts have been made in Russia and Europe to fly an inflatable decelerator. The first flight model of an inflatable decelerator was on the penetrators for the MARS-96 mission which failed to leave Earth orbit. The second two attempts were the inflatable reentry descent technology demonstrators. Though the MARS-96 mission and IRDT missions are 
entry missions, they encounter similar flight conditions as an aerocapture mission.

\subsection{MARS-96 Penetrators}

The MARS-96 mission carried two penetrators with surface science and seismology payloads. The penetrator configuration consisted of a long spike with a small rigid cone and an inflatable brake [77]. Fig. 20 shows the penetrator layout with the rigid and inflatable brakes identified. The penetrators were to be released during Mars approach and intersect the atmosphere at $5.6 \mathrm{~km} / \mathrm{s}$ and $-12^{\circ} \pm 2^{\circ}$ flight path angle. Each penetrator had a mass of $45 \mathrm{~kg}$ and carried a $4.5 \mathrm{~kg}$ scientific payload. Decelerator size was designed to achieve ground impact at $80 \pm 20 \mathrm{~m} / \mathrm{s}$, resulting in ground penetration up to $6 \mathrm{~m}$. The inflatable brake was a second stage decelerator designed to deploy at Mach 15 during the Mars atmospheric entry. Unfortunately, on November 16, 1996, the MARS-96 upper stage failed to ignite and the spacecraft re-entered the Earth's atmosphere terminating the mission.

\subsection{Inflatable Reentry Descent Technology}

Due to the upper-stage failure of the MARS-96 penetrator mission, an Earth test was proposed for this ballute technology. The test flight planned the return of an instrumented payload from Earth orbit using a two stage conical ballute. The mission and vehicle parameters are given in [78] and [79]. The layout and critical dimension of the vehicle are shown in Fig. 21. The aerodynamic decelerator mission profile begins with inflation of the $1^{\text {st }}$ stage ballute while still attached to the Fregat upper stage. Separation is commanded and the IRDT ballute encounters the Earth's atmosphere at $100 \mathrm{~km}$ altitude, $5.4 \mathrm{~km} / \mathrm{s}$, and $-7.3^{\circ}$ flight path angle. The second stage ballute is deployed at about $30 \mathrm{~km}$ altitude and increases the ballistic coefficient by a factor of 5, allowing a slow final descent and impact at $14 \mathrm{~m} / \mathrm{s}$. Table 5 lists the planned critical events during entry.

Table 5. Critical events during entry for IRDT.

\begin{tabular}{lcc}
\hline & Value & Altitude \\
\cline { 2 - 3 } Deorbit burn & & $600 \mathrm{~km}$ \\
$1^{\text {st }}$ stage deploy & $\mathrm{T}=0 \mathrm{~s}$ & $200 \mathrm{~km}$ \\
Separation from LV & $5.4 \mathrm{~km} / \mathrm{s},-7.3^{\circ}$ & $150 \mathrm{~km}$ \\
Entry interface & $31.3 \mathrm{~W} / \mathrm{cm} 2$ & $61 \mathrm{~km}$ \\
Peak heat rate & $13.5 \mathrm{~g}$ & $53 \mathrm{~km}$ \\
Peak acceleration & & $30 \mathrm{~km}$ \\
$2^{\text {nd }}$ stage deploy & & $0 \mathrm{~km}$ \\
Ground impact & & \\
\hline
\end{tabular}

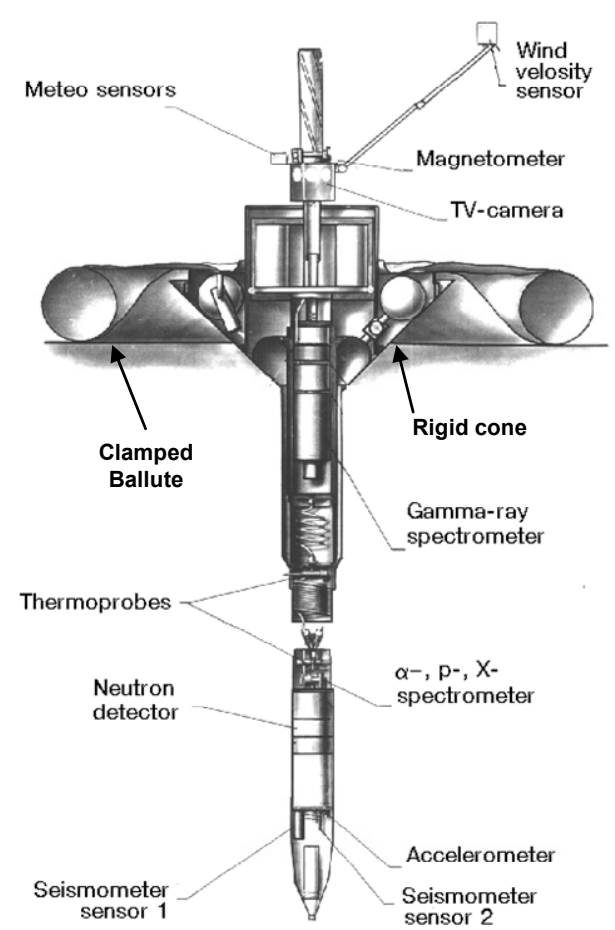

Figure 20. MARS-96 penetrator schematic showing the rigid cone and clamped ballute [77].

The IRDT test flight took place in February of 2000 aboard a Soyuz/Fregat launch vehicle. Ref. [79] describes the post-flight recovery and trajectory reconstruction efforts. Upon recovery of the vehicle, inspection revealed destroyed $1^{\text {st }}$ and $2^{\text {nd }}$ stage ballutes, higher than expected ablation of the thermal protection system, full $2^{\text {nd }}$ stage gas bottles, and an impact damaged payload container. Despite the loss of the inflatables and damage to the payload canister, the instruments recorded the flight data and this data was successfully retrieved. Linear acceleration, angular acceleration, pressure, and temperature measurements were recorded. Data recording was started at $150 \mathrm{~km}$ altitude, prior to the $100 \mathrm{~km}$ atmospheric interface. Several spikes in the acceleration curve were noted shortly after the start of recording. These spikes are indicative of impact with a foreign object, most likely the payload adapter of the upper stage that induced a tumbling motion, later damped by aerodynamic forces. Upon entry, forces were primarily in the axial direction, indicating proper functioning of the ballute, but about $50 \mathrm{~s}$ after entry interface (near peak deceleration) the capsule began to tumble again. The tumbling motion exposed the back of the payload where the pressure sensor is mounted, and increased pressure is observed in the readings corresponding to this region of the trajectory. After about $90 \mathrm{~s}$, the tumbling motion was damped and the vehicle descended at about $60 \mathrm{~m} / \mathrm{s}$, 
significantly above the nominal rate of $14 \mathrm{~m} / \mathrm{s}$. The increased descent rate correlates well with the drag produced by the rigid core of the vehicle alone, indicating failure of both ballute stages. A definitive cause of failure was not determined. The Fregat upper stage was also outfitted with a scaled up version of the IRDT ballute. The Fregat stage entered, but was not recovered.

Since the initial IRDT flight was largely unsuccessful a reflight was planned (IRDT-2). Reference [ 80 ] describes the improvements to the heatshield design, pressure control system, data acquisition and telemetry system. Improvements were based on the desire for more complete information in the case of a failure. The packaged layout for IRDT-2 is shown in Fig. 22. The system has a mass of $140 \mathrm{~kg}, 30 \mathrm{~kg}$ more than IRDT due to the extra instrumentation. This flight was initiated on a Russian Volna submarine launched rocket and would simulate a $7.8 \mathrm{~km} / \mathrm{s}$ entry at $-2^{\circ}$ flight path angle. Launch occurred on July 7, 2001 but the payload failed to separate from the launch vehicle and the vehicle was never found. An identical reflight named IRDT-2R is currently scheduled for July 2005 [81].

\section{ADVANCING BALLUTE TECHNOLOGY}

Numerous studies have shown the mass advantage of using ballutes for aerocapture and entry. Recent advances in materials technology and integrated aerothermal-structural analysis, have spurred a new round of research to develop the concept further. This work is critically focused on advancing the technology readiness of fabric and thin-film ballute concepts leading to flight validation.

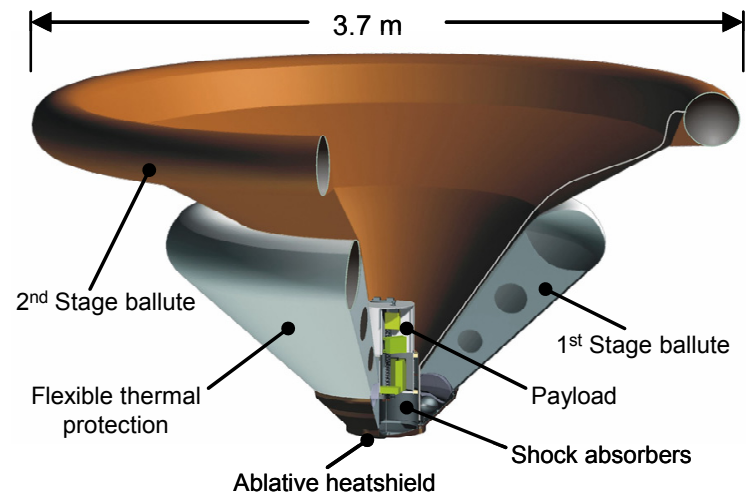

Figure 21. IRDT configuration [79].

The inflatable reentry vehicle experiment (IRVE) is currently being developed at NASA Langley Research Center. A clamped fabric ballute composed of concentric toroids is being designed for launch on a sounding rocket [82]. While not entering from orbit, the resulting trajectory will approximate the heating and loads encountered during Earth entry. Fig. 23 shows a schematic of the layout of the IRVE vehicle. Launch is scheduled for November 2005.

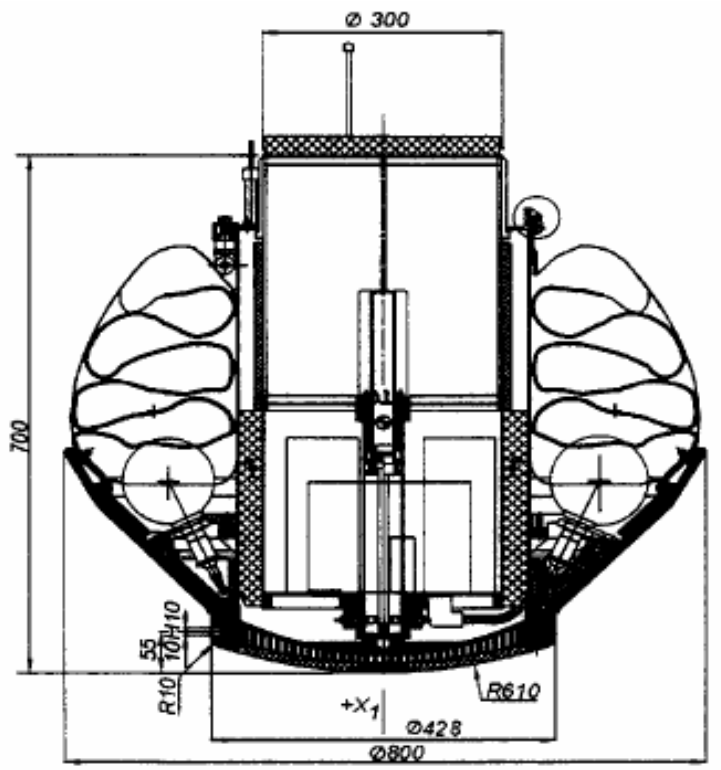

Figure 22. Packaging layout for IRDT-2 [80].

The $2^{\text {nd }}$ young engineers' satellite (YES2) project is a completely student built project started in 2002. Ref. [83] describes the mission, detailing the use of a tether to de-orbit and "an inherently safe reentry" (AIR) capsule for entry and landing in mainland Europe. AIR is considered inherently safe because it is designed to burn up in the upper atmosphere if inflation does not occur, and if it works properly the descent speed will be extremely low. The final configuration is to have a mass between 5 and $10 \mathrm{~kg}$ and have a terminal velocity of $\sim 7$ $\mathrm{m} / \mathrm{s}$. Ref. [84] outlines the evolution of the AIR design from a simple inflatable sphere to the inflated spherecone specified for the mission. Details and performance of the final configuration are provided in [85]. Fig. 24 shows a cross-section of the final configuration.

Numerous systems studies and tool development programs are supporting development of ballutes for aerocapture and entry. A majority of the ballute work in progress is sponsored either through NASA's In-Space Propulsion (ISP) [86] or Exploration Systems Research and Technology programs. A representative set of this technology development work is described here.

The ongoing ISP work is focused on a comparison of thin-film ballute aerocapture to rigid aeroshell aerocapture at Titan and Neptune for a $500 \mathrm{~kg}$ science payload. Current results are summarized in [44], and 
show that the payload mass fraction is significantly improved using thin-film ballutes. The mission profile uses binary drag modulation to control the exit conditions. The conceptual design study includes aerothermal, packaging, structural, and trajectory analysis and has found no show stoppers. Limited wind tunnel testing has been performed on simplified models to verify analyses. Future work includes aeroelastic analysis, incorporation of tethers aerodynamics and wind tunnel testing of inflated models.

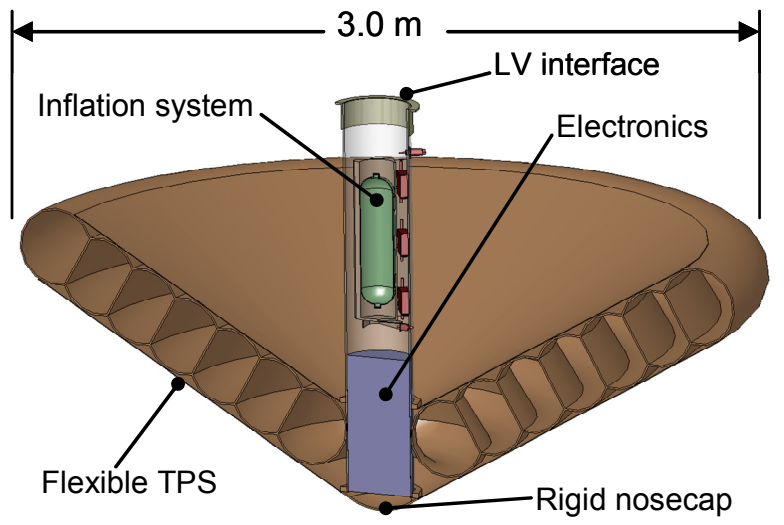

Figure 23. Schematic of IRVE vehicle.

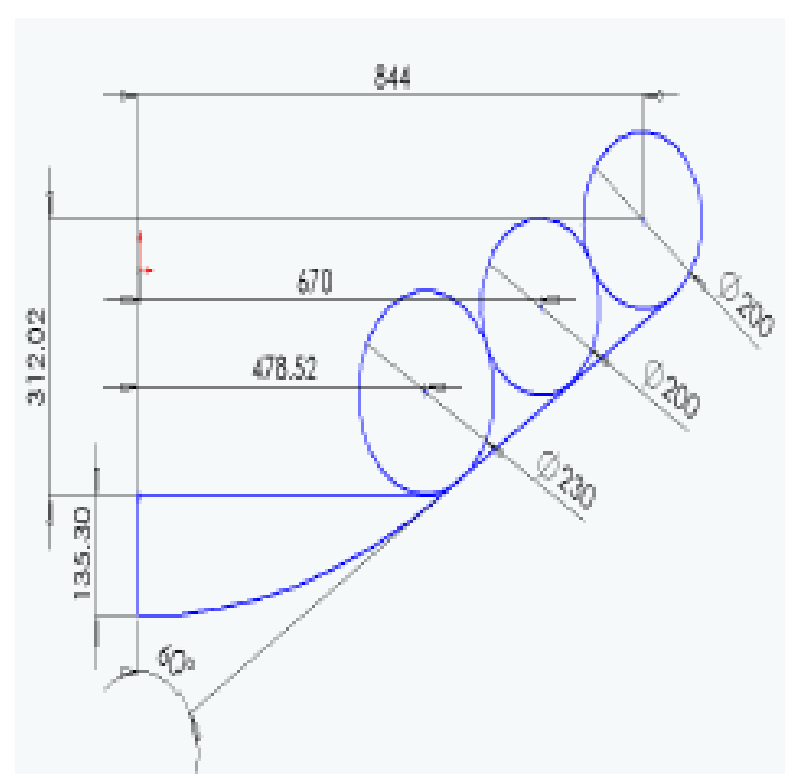

Figure 24. Cross section of the AIR final configuration showing the three toroid construction [85].

Ballute research sponsored by the NASA ESR\&T technology program focuses on ISS downmass, Earth return from the Moon and abort options for the Crew Exploration Vehicle. Both direct entry and aerocapture into a low Earth orbit are being considered. These analysis efforts incorporate integrated systems design, aeroelasticity, and materials evaluation. Wind tunnel testing in support of the analytic effort is also planned.

With sufficient investment, the fidelity and accuracy of integrated analysis capabilities will continue to advance. Current capability includes static aeroelastic analysis. CFD codes for entry and aerocapture applications with moving boundaries are being developed, and dynamic aeroelastic solutions along with flutter solutions will be available within five years in all flight regimes. If the current level of technology investment continues, a successful flight test of a clamped ballute will occur in the next five years. Under these same assumptions, the requisite analysis and hypersonic ground-based testing for a thin-film trailing ballute will also be completed within five years, paving the way for flight test of this technology.

\section{SUMMARY}

The concept of the ballute was first theorized in the early 1960 's. In the late 1970 's and early 1980 's, the first ballute aerocapture analyses were completed, identifying a number of technical challenges including the ability to provide lift modulation, sufficient materials thermal-structural characteristics, aerostability and seam heating. In 1999 and 2000, a resurgence in effort was initiated that continues to the present, in large part due to the concept of the trailing ballute. A number of ballute technical challenges have been documented and the aeroassist community is presently focused on their solution. There is significant interest in applying ballute technology at the Earth and in other planetary atmospheres. Though detailed studies have not been completed, preliminary analysis indicates feasibility and significant mass savings over propulsive orbit insertion.

The issue of optimal ballute shape is tightly coupled with the flow stability problem and the application. For aerocapture at Titan, a toroidal geometry has been analyzed in all flight regimes and shown to produce steady flow (including the interference effects of the parent spacecraft). Tethers were not included, but separate analysis was conducted to determine the heat rate on the tethers and insulation was added as necessary. Material testing of thin-film polymers has indicated adequate strength at temperature to survive the drag forces with minimal reinforcements at the tether attach points. Mechanical tests of seaming techniques are underway and indicate feasibility. Parent spacecraft protection was addressed through modelling and it was determined that insulation blankets would be sufficient to protect the spacecraft from the heating environment encountered. Trajectory work, and ballute 
release algorithm development has indicated that ballute aerocapture at Titan is feasible when uncertainties are accounted for. Minimal wind tunnel testing has been performed to date, with the limited tests conducted being aimed at validation of computational methods. Challenges still exist for the Titan aerocapture mission, specifically aeroelastic analysis, deployment, radiative heating, and experimental verification.

Efforts are currently underway to develop the tools necessary for aeroelastic analysis. Once developed, these tools will require experimental validation. Deployment techniques for large pressure stabilized structures can be advanced from efforts in solar sails and inflatable antennas, but specific implementation options require adaptation to ballute geometries.

Determination of radiative heat rate is a major outstanding issue, particularly in the transitional aerodynamic regime. In the 1980's theories were developed that agreed with data from flight test at Earth with reasonable accuracy, but were not know to be valid at the altitudes where ballutes decelerate. Furthermore, limited data is available to validate gasdynamic models for other planetary atmospheres.

Additional technology development in the areas of integrated analysis, high temperature materials and hypersonic testing will result in advancement of thinfilm ballute technology to the flight-test stage and completion of attached fabric ballute technology flight testing within the next five years. With completion of these analysis and flight test programs, incorporation of ballute technology as part of a planetary exploration mission will soon become a viable option.

\section{REFERENCES}

${ }^{1}$ Warzecha, L. W., "Performance and Design Considerations for Maneuvering Space Vehicles," IAS Paper 60-59, IAS National Summer Meeting, June 28July $1,1960$.

${ }^{2}$ London, H. S., "Change of Satellite Orbit Plane by Aerodynamic Maneuvering," IAS $29^{\text {th }}$ Annual Meeting, New York, NY, 1961. Also in Journal of the Aerospace Sciences, Vol. 29, No. 3, March 1962, pp. 323-332. ${ }^{3}$ Kayser, L. D., "Pressure Distribution, Heat Transfer, and Drag Tests on the Goodyear Ballute," AEDC-TDR62-39, March 1962.

${ }^{4}$ Walberg, G. D., "A Review of Aeroassisted Orbit Transfer," Journal of Spacecraft and Rockets, vol. 22, no. 1, 1985, pp. 3-18. Also available as AIAA Paper 821378.
${ }^{5}$ Hall, J. L., and Le, A. K., "Aerocapture Trajectories for Spacecraft with Large, Towed Ballutes," Advances in the Astronautical Sciences, Univelt Incorporated, San Diego, CA, vol. 108 II, pp. 1857-1872, 2001. Also available as: AAS Paper 01-235.

${ }^{6}$ NASA Space Science Strategic Plan, Nov. 2000. http://www.hq.nasa.gov/office/codez/plans/SSE00plan. pdf, accessed on June 17, 2005.

${ }^{7}$ Hall, J. L., Noca, M. A., and Bailey, R. W., "CostBenefit Analysis of the Aerocapture Mission Set," Journal of Spacecraft and Rockets, vol. 42, no. 2, Mar.Apr. 2005, pp. 309-320.

${ }^{8}$ Maynard, J. D., "Aerodynamic Characteristics of Parachutes at Mach Numbers from 1.6 to 3," NASATN-D-752, May, 1961.

${ }^{9}$ McShera, J. T., Jr., and Keyes, J. W., "Wind-Tunnel Investigation of a Balloon as a Towed Decelerator at Mach Numbers from 1.47 to 2.50," NASA-TN-D-919, Aug., 1961.

${ }^{10}$ Charczenko, N., and McShera, J. T., Jr.,

"Aerodynamic Characteristics of Towed Cones Used as Decelerators at Mach Numbers from 1.57 to 4.65," NASA-TN-D-994, Dec. 1961.

${ }^{11}$ McShera, J. T., Jr., "Aerodynamic Drag and Stability Characteristics of Towed Inflatable Decelerators at Supersonic Speeds," NASA-TN-D-1601, Mar., 1963.

${ }_{12}$ Couch, L. N., "Drag and Stability Characteristics of a Variety of Reefed and Unreefed Parachute

Configurations at Mach 1.80 with an Empirical Correlation for Supersonic Mach Numbers," NASATR-R-429, Feb. 1975.

${ }^{13}$ Alexander, W. C., "A Discussion of Governing Decelerator Performance and Design Parameters in the Supersonic Flight Regime," AIAA Paper 68-938, $2^{\text {nd }}$ AIAA Aerodynamic Deceleration Systems Conference, El Centro, CA, Sept. 23-25, 1968.

${ }^{14}$ Alexander, W. C., and Lau, R. A., "State-of-the-Art Study for High-Speed Deceleration and Stabilization Devices," NASA-CR-66141, Sept. 1966.

${ }^{15}$ Musil, J. L., "Study of Expandable, Terminal Decelerators for Mars Atmosphere Entry," Report GER-12842 vol. 1, Goodyear Aerospace Corporation, Akron, OH, Oct. 21, 1966.

${ }^{16}$ McShera, J. T., Jr., and Bohon, H. L., "A Summary of Supersonic Decelerators with Emphasis on Problem Areas in Aerodynamics and Structures," AIAA Paper $67-201,5^{\text {th }}$ AIAA Aerospace Sciences Meeting, New York, NY, Jan. 23-26, 1967.

${ }^{17}$ Guy, L. D., "Structural and Decelerator Design Options for Mars Entry," Journal of Spacecraft, vol. 6, no. 1, Jan. 1969, pp. 44-49. Also available as AIAA paper 68-344. 
${ }^{18}$ Gillis, C. L., "Deployable Aerodynamic Decelerators for Space Missions," Journal of Spacecraft, vol. 6, no. 8, Aug. 1969, pp. 885-890. Also available as AIAA Paper 68-1081.

${ }^{19}$ Andrews, D. G., and Bloetscher, F., "Aerobraked Orbital Transfer Vehicle Definition," AIAA Paper 81$0279,19^{\text {th }}$ AIAA Aerospace Sciences Meeting, St. Louis, MO, Jan. 12-15, 1981.

${ }^{20}$ Grenich, A. F., and Woods, W. C., "Flow Field Investigation of Atmospheric Braking for High Drag Vehicles with Forward Facing Jets in Spacecraft Entry," AIAA Paper 81-0293, $19^{\text {th }}$ AIAA Aerospace Sciences Meeting, St. Louis, MO, Jan. 1981.

${ }^{21}$ Heitchue, R. D., "Emergency Space Station Escape System Consisting of Retrorocket, Expandable Reentry Structure, Life Support Unit, Survival Provisions and Communications Beacons," Advances in the Astronautical Sciences, vol. 16, no. 1, AAS Space Renedezvous, Rescue, and Recovery, Edited by N. V. Peterson, Western Periodicals Co., North Hollywood, CA, 1963, pp. 680-692.

${ }^{22}$ Kendall, R. T., "Techniques for Space and Hypersonic Flight Escape," Proceedings of SAE Aerospace Systems Conference, Los Angeles, CA, June 27-30, 1967, pp. 394-400.

${ }^{23}$ Kendall, R. T., Jr., and Kendall, R. T. Sr., "Advanced Unmanned/Manned Space Payload Inflatable Decelerator/Delivery System," AIAA Paper 95-3798, AIAA Space Programs and Technologies Conference, Huntsville, AL, Sep. 26-28, 1995.

${ }^{24}$ Kendall, R. T. and Maddox, A. R., "The Use of Inflatable Structures for Re-entry of Orbiting Vehicles," SAE Paper 901835, Aerospace Technology Conference and Exposition, Long Beach, CA, Oct. 1-4, 1990.

${ }^{25}$ Cruz, M. I., "The Aerocapture Vehicle Mission Design Concept," Conference on Advanced Technology for Future Space Systems, Hampton, VA, May 8-10, 1979, pp. 195-201. Also available as AIAA Paper 790893.

${ }^{26}$ Wercinski, P. F., et al, "Trajectory, Aerothermal Conditions, and Thermal Protection System Mass for the Mars 2001 Aerocapture Mission," AIAA Paper 97$0472,35^{\text {th }}$ Aerospace Sciences Meeting and Exhibit, Reno, NV, Jan. 6-10, 1997.

${ }^{27}$ French, J. R., and Cruz, M. I., "Aerobraking and Aerocapture for Planetary Missions," Astronautics and Aeronautics, vol. 18, Feb. 1980, pp. 48-55, 71.

${ }^{28}$ Braun, R. D. and Powell, R. W. "Aerodynamic Requirements of a Manned Mars Aerobraking Transfer Vehicle." Journal of Spacecraft \& Rockets, Vol. 28, No. 4, pp. 361-367, July-August 1991.

${ }^{29}$ Braun, R. D., Powell, R. W., and Lyne, J. E., "Earth Aerobraking Strategies for Manned Return from Mars,"
Journal of Spacecraft and Rockets, vol. 29, no. 3, pp. 297-304, May-June 1992.

${ }^{30}$ Powell, R. W., and Braun, R. D., “A Six Degree-ofFreedom Guidance and Control Analysis of Mars Aerocapture," Journal of Guidance, Control and Dynamics, vol. 16, no. 6, pp. 1038-1044, Nov.-Dec. 1993.

${ }^{31}$ Mulqueen, J. A., "Applications of Low Lift to Drag Ratio Aerobrakes Using Angle of Attack Variation for Control," NASA-TM-103544, June, 1991.

32 Jits, R. Y., and Walberg, G. D., "High L/D Mars Aerocapture for 2001, 2003, and 2005 Mission Opportunities," AIAA Paper 1998-0299, $36^{\text {th }}$ Aerospace Sciences Meeting, Reno, NV, Jan. 12-15, 1998.

${ }^{33}$ Ling, L., Baseggio, F. M., and Fuhry, D. P., "Parametric Entry Corridors for Lunar/Mars Aerocapture Missions," NASA-TM-102178, April, 1991.

${ }^{34}$ Kustas, F. M., et al, "Inflatable Decelerator Ballute for Planetary Exploration Spacecraft," AIAA Paper 2000-1795, $41^{\text {st }}$ AIAA/ASME/ASCE/AHS/ASC Structures, Structural Dynamics, and Materials Conference and Exhibit, Atlanta, GA, Apr. 3-6, 2000.

${ }^{35}$ Kustas, F. M., et al, "Attached Inflatable Ballute for Spacecraft Deceleration," Proceedings of the IEEE Aerospace Conference, vol. 7, pp. 421-427, 2000.

${ }^{36}$ McRonald, A. D., "A Light-Weight Inflatable Hypersonic Drag Device for Planetary Entry," AIAA Paper 99-0422, Association Aeronautique de France Conference, Arcachon, France, Mar. 16-18, 1999.

${ }^{37}$ Cruz, J. R., Cianciolo, A. D., Powell, R. W., Simonsen, L. C., and Tolson, R. H., "Entry, Descent, and Landing Technology Concept Trade Study for Increasing Payload Mass to the Surface of Mars," $4^{\text {th }}$ International Symposium on Atmospheric Reentry Vehicles and Systems, Arcachon, France, Mar. 21-23, 2005.

${ }^{38}$ Yavrouian, A., Yen, S. P. S., Plett, G., and Weissman, N., "High Temperature Materials for Venus Balloon Envelopes," AIAA Paper 95-1617, $11^{\text {th }}$ AIAA LighterThan-Air Systems Technology Conference, Clearwater, FL, May 16-18, 1995.

${ }^{39}$ Yavrouian, A., Plett, G., Yen, S. P. S., Cutts, J., and Baek, D., "Evaluation of Materials for Venus Aerobot Applications," AIAA Paper 99-3859, $13^{\text {th }}$ Lighter-ThanAir Systems Technology Conference, Norfolk, VA, June 28-July 1, 1999.

${ }^{40}$ McRondald, A. D., "A Light-Weight Inflatable Hypersonic Drag Device for Venus Entry," AAS Paper 99-355, AAS/AIAA Astrodynamics Specialist Conference, Girdwood, AK, Aug. 16-19, 1999.

${ }^{41}$ McRonald, A. D., "A Light-Weight Inflatable Hypersonic Drag Device for Neptune Entry," AIAA 
Paper 2000-123, AAS/AIAA Space Flight Mechanics Meeting, Clearwater, FL, Jan. 23-26, 2000.

${ }^{42}$ Hall, J., L., "A Review of Ballute Technology for Planetary Aerocapture," AIAA Paper 2000-382, $4^{\text {th }}$ IAA conference on Low Cost Planetary Missions, Laurel, MD, May 2-5, 2000.

${ }^{43}$ Freeland, R. E., et al, "Large Inflatable Deployable Antenna Flight Experiment Results," Acta Astronautica, vol. 41, no. 10, 1997, pp. 267-277.

${ }^{44}$ Miller, K. L., et al, "Trailing Ballute Aerocapture: Concept and Feasibility Assessment," AIAA Paper 2003-4655, $39^{\text {th }}$ AIAA /ASME/SAE/ASEE Joint Propulsion Conference and Exhibit, Huntsville, AL, July 20-23, 2003.

${ }^{45}$ Westhelle, C. H., and Masciarelli, J. P., "Assessment of Aerocapture Flight at Titan Using a Drag-Only Device," AIAA Paper 2003-5389, AIAA Atmospheric Flight Mechanics Conference and Exhibit, Austin, TX, Aug. 11-14, 2003.

${ }^{46}$ Johnson, W. R., and Lyons, D. T., "Titan Ballute Aerocapture Using a Perturbed TitanGRAM Model," AIAA Paper 2003-5280, AIAA Atmospheric Flight Mechanics Conference and Exhibit, Austin, TX, Aug. 11-14, 2003.

${ }^{47}$ Lyons, D. T., and Johnson, W. R., "Ballute Aerocapture Trajectories at Neptune," AIAA Paper 2004-5181, AIAA Atmospheric flight Mechanics Conference and Exhibit, Providence, RI, Aug. 16-19, 2004.

${ }^{48}$ Houtz, N. E., "Optimization of Inflatable Drag Devices by Isotensoid Design," AIAA Paper 64-437, $1^{\text {st }}$ AIAA Annual Meeting, Washington, D.C., Jun. 29-July 2, 1964.

${ }^{49}$ Anderson, R. A., "Structures Technology - 1964," Astronautics and Aeronautics, vol. 2, no. 12, Dec. 1964, pp. 14-20.

${ }^{50}$ Anderson, M. S., et al, "A Tension Shell Structure for Application to Entry Vehicles," NASA-TN-D-2675, Mar. 1965.

${ }^{51}$ Weeks, G. E., "Buckling of a Pressurized Toroidal Ring Under Uniform External Loading," NASA-TN-D4124, Aug., 1967.

${ }^{52}$ Kyser, A. C., "Deployment Mechanics for an Inflatable Tension-Cone Decelerator," NASA-CR-929, Nov., 1967.

${ }^{53}$ Prada y Nogueira, I. A., Forlivesi, F., and Morel, Q., "The FEM Applicability for the First-Stage Design of Inflatable Bodies. Iterative Methodology Between FD and FEM for the Inherently Safe Re-Entry Capsule for YES2. The Breogan Leakage Protection System," IAC Paper 03-U.3.04, 54 ${ }^{\text {th }}$ International Astronautical Congress of the International Astronautical Federation, Bremen, Germany, Sep. 29-Oct. 3, 2003.
${ }^{54}$ Wang, J. T., Chen, T., Sleight, D. W., and Tessler, A., "Simulating Nonlinear Deformations of Solar Sail Membranes Using Explicit Time Integration," AIAA Paper 2004-1580, $45^{\text {th }}$ AIAA/ASME/ASCE/AHS/ASC Structures, Structural Dynamics, and Materials Conference, Palm Springs, CA, Apr. 19-22, 2005.

${ }^{55}$ Tessler, A., Sleight, D. W., and Wang, J. T., "Nonlinear Shell Modeling of Thin Membranes with Emphasis on Structural Wrinkling," AIAA Paper 2003$1931,44^{\text {th }}$ AIAA/ASME/ASCE/AHS/ASC Structures, Structural Dynamics, and Materials Conference, Norfolk, VA, Apr. 7-10, 2003.

${ }^{56} \mathrm{Su}$, X., Abdi, F., Taleghani, B., and Blandino, J. R., "Wrinkling Analysis of a Kapton Square Membrane Under Tensile Loading," AIAA Paper 2003-1985, $44^{\text {th }}$ AIAA/ASME/ASCE/AHS Structures, Structural Dynamics, and Materials Conference, Norfolk, VA, Apr. 7-10, 2003.

${ }^{57}$ Gnoffo, P. A., "Planetary-Entry Gas Dynamics," Annual Review of Fluid Mechanics, vol. 31, 1999, pp. 459-494.

${ }^{58}$ Rasheed, A., Fujii, K., Hornung, H. G., and Hall, J. L. "Experimental Investigation of the Flow Over a Toroidal Aerocapture Ballute," AIAA Paper 2001-2460, $19^{\text {th }}$ AIAA Applied Aerodynamics Conference, Anaheim, CA, June 11-14, 2001.

${ }_{59}$ McIntyre, T. J., et al, "Experimental Expansion Tube Study of the Flow Over a Toroidal Ballute," Journal of Spacecraft and Rockets, vol. 41, no. 5, Sept.-Oct., 2004, pp. 716-725.

${ }^{60}$ Hornung, H. G., "Hypersonic Flow Over Bodies in Tandem," Shock Waves, vol. 11, no. 6, May, 2002, pp. 441-445. Also available as AIAA Paper 2001-2776. ${ }^{61}$ Gnoffo, P. A., "An Upwind-Biased, Point-Implicit Relaxation Algorithm for Viscous Compressible Perfect Gas Flows," NASA-TP-2953, Feb. 1990.

${ }^{62}$ Gnoffo, P. A., "Computational Aerothermodynamics in Aeroassist Application," Journal of Spacecraft and Rockets, vol. 10, no. 3, 2003, pp. 305-312. Also available as AIAA Paper 2001-2632.

${ }^{63}$ Gnoffo, P. A., Gupta, R. N., and Shinn, J. L., "Conservation Equations and Physical Models for Hypersonic Air Flows in Thermal and Chemical Nonequilibrium," NASA-TP-2867, 1989.

${ }^{64}$ Gnoffo, P. A., and Anderson, B. P., "Computational Analysis of Towed Ballute Interactions," AIAA Paper 2002-2997, $8^{\text {th }}$ AIAA/ASME Joint Thermosphysics and Heat Transfer Conference, Saint Louis, MO, June 2426, 2002.

${ }^{65}$ Anderson, B. P., "Computational Continuum and Rarefied Flow Results for Ballute Applications," AIAA Paper 2004-292, $42^{\text {nd }}$ AIAA Aerospace Sciences Meeting and Exhibit, Reno, NV, Jan. 5-8, 2004. 
${ }^{66}$ Park, C., "A Survey of Aerobraking Orbital Transfer Vehicle Design Concepts," AIAA Paper 87-514, 25 ${ }^{\text {th }}$

AIAA Aerospace Sciences Meeting, Reno, NV, Jan. 12$15,1987$.

${ }^{67}$ Park, C., "Theory of Idealized Two-Dimensional Ballute in Newtonian Hypersonic Flow," Journal of Spacecraft and Rockets, vol. 25, no. 3, 1988, pp. 217224. Also available as: AIAA Paper 86-301.

${ }^{68}$ Abe, T., "A Self-Consistent Tension Shell Structure for Application to Aerobraking Vehicle and Its Aerodynamic Characteristics," AIAA Paper 88-3405, AIAA/ASME/SAE/ASEE $24^{\text {th }}$ Joint Propulsion Conference, Boston, MA, July 11-13, 1988.

${ }^{69}$ Mosseev, Y., "The Multipurpose Integrated PCSoftware for Structural and Aeroelastic Analysis of Decelerators, Paragliders and Balloons," AIAA Paper 97-1455, $14^{\text {th }}$ AIAA Aerodynamic Decelerator Systems Technology Conference, San Francisco, CA, June 3-5, 1997.

${ }^{70}$ Mosseev, Y., "The Decelerator Pitch-Dependent Performances Prediction Based on 3D Aeroelastic Analysis," AIAA Paper 99-1717, $15^{\text {th }}$ CEAS/AIAA Aerodynamic Decelerator Systems Technology Conference, Toulouse, France, June 8-11, 1999.

${ }^{71}$ Bartels, R. E., et al, "A Proposed Role of Aeroelasticity in NASA's New Exploration Vision," Paper IF-013, International Forum on Aeroelasticity and Structural Dynamics, Munich, Germany, June 28-July $1,2005$.

${ }^{72}$ Thuruthimattam, B. J., Friedmann, P. P., McNamara, J. J., and Powell, K. G., "Aeroelasticity of a Generic Hypersonic Vehicle," AIAA Paper 2002-1209, 43 ${ }^{\text {rd }}$ AIAA/ASME/ASCE/AHS Structures, Structural Dynamics, and Materials Conference, Denver, CO, Apr. 22-25, 2002.

${ }^{73}$ Graham, J. J. Jr., "Development of Ballute for Retardation of Arcas Rocketsondes," AFCRL-65-877, Dec. 1965.

${ }^{74}$ Mayhue, R. J., and Eckstrom, C. V., "Flight-Test Results from Supersonic Deployment of an 18-FootDiameter (5.49-Meter) Towed Ballute Decelerator," NASA-TM-X-1773, May 1969.

${ }^{75}$ White, W. E., and Riddle, C. D., "An Investigation of the Deployment Characteristics and Drag Effectiveness of the Gemini Personnel Decelerator at Subsonic and Supersonic Speeds, Phase II," AEDC-TDR-63-255, Dec. 1963.

${ }^{76}$ Smith, T. R., et al, "Ballute and Parachute Decelerators for FASM/QuickLook UAV," AIAA Paper 2003-2142, $17^{\text {th }}$ AIAA Aerodynamic Decelerator Systems Technology Conference and Seminar, Monterey, CA, May 19-22, 2003.
${ }^{77}$ Editor: Zacharov, A., "MARS-96," http://www.iki.rssi.ru/mars96/09_mars_e.htm, accessed on June 13, 2005.

${ }^{78}$ Ivanov, S. V., et al, "New Technology of Payload Return from Space to the Earth," Paper IAF-00-V.2.04, $51^{\text {st }}$ International Astronautical Congress, Rio de Janeiro, Brazio, Oct. 2-6, 2000.

${ }^{79}$ Gräßlin, M., and Schöttle, U., "Flight Performance Evaluation of the Re-Entry Mission IRDT-1," Paper IAF-01-V.3.05, 52 ${ }^{\text {nd }}$ International Astronautical Contress, Toulouse, France, Oct. 1-5, 2001.

${ }^{80}$ Wilde, D., and Walther, S., "Flight Test and ISS Application of the Inflatable Reentry and Descent Technoloty (IRDT)," Acta Astronautica, vol. 51, no. 19, 2002, pp. 83-88. Also available as: Paper IAF-01T.2.02.

${ }^{81}$ European Space Agency, "ESA Permanent Mission in Russia," http://www.esa.int/SPECIALS/ESA_Permanent_Missio n_in_Russia/SEM8DY0DU8E_0.html, accessed on June $13,2005$.

${ }^{82}$ Hughes, S. J., et al, "Inflatable Re-Entry Vehicle Experiment (IRVE) Design Overview," AIAA Paper 2005-1636, $18^{\text {th }}$ AIAA Aerodynamic Decelerator Systems Technology Conference and Seminar, Minich, Germany, May 23-26, 2005.

${ }^{83}$ Kruijff, M., Van de Heide, E. J., and Calzada Gil, S., "YES2 Inherently-Safe Tethered Re-Entry Mission and Contingencies," Paper IAC-03-IAA.6.2.02, 54 ${ }^{\text {th }}$ International Astronautical Congress of the International Astronautical Federation, Bremen, Germany, Sep. 29-Oct.3, 2003.

${ }^{84}$ Kruijff, M., Van der Heide, E. J., Dragoni, E., Castagnetti, D., and Ferretti, S., "Concept Selection and Design of the Inherently Safe Re-Entry Capsule for YES2," Paper IAC-03-V.3.08, 54 ${ }^{\text {th }}$ International Astronautical Congress of the International Astronautical Federation, Bremen, Germany, Sep. 29Oct.3, 2003.

${ }^{85}$ Morel, Q., Hobbs, S., and Kruijff, M., "Cranfield's Inherently Safe Re-Entry Capsule Design for YES2," Paper IAC-03-U.1.07, 54 ${ }^{\text {th }}$ International Astronautical Congress of the International Astronautical Federation, Bremen, Germany, Sep. 29-Oct.3, 2003.

${ }^{86}$ James, B., Munk, M., and Moon, S., "Aerocapture Technology Project Overview," AIAA Paper 2003$4654,39^{\text {th }}$ AIAA/ASME/SAE/ASEE Joint Propulsion Conference and Exhibit, Huntsville, AL, July 20-23, 2003. 